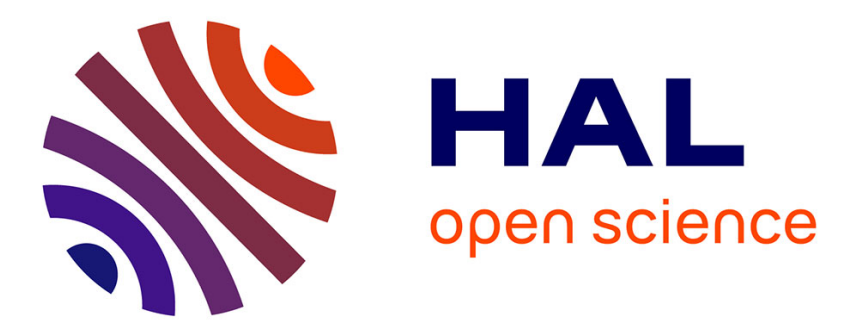

\title{
Enhancing the biodegradation efficiency of a emergent refractory water pollutant by a bacterial isolate through a statistical process optimization approach
}

\author{
Lidia Favier, C.V. Ungureanu, A.I. Simion, G.-E. Bahrim, Christophe Vial
}

\section{To cite this version:}

Lidia Favier, C.V. Ungureanu, A.I. Simion, G.-E. Bahrim, Christophe Vial. Enhancing the biodegradation efficiency of a emergent refractory water pollutant by a bacterial isolate through a statistical process optimization approach. Process Safety and Environmental Protection, 2021, 148, pp.11331145. 10.1016/j.psep.2021.02.012 . hal-03196088

\section{HAL Id: hal-03196088 \\ https://hal.science/hal-03196088}

Submitted on 16 Apr 2021

HAL is a multi-disciplinary open access archive for the deposit and dissemination of scientific research documents, whether they are published or not. The documents may come from teaching and research institutions in France or abroad, or from public or private research centers.
L'archive ouverte pluridisciplinaire HAL, est destinée au dépôt et à la diffusion de documents scientifiques de niveau recherche, publiés ou non, émanant des établissements d'enseignement et de recherche français ou étrangers, des laboratoires publics ou privés. 


\section{Enhancing the biodegradation efficiency of a emergent refractory water pollutant by a bacterial isolate through a statistical process optimization approach}

\section{Lidia Favier $^{a^{*}}$, Claudia Popa Ungureanu ${ }^{\mathrm{b}}$, Andrei Ionut Simion ${ }^{\mathrm{c}}$, Gabriela Bahrim ${ }^{\mathrm{b}}$, Christophe Vial ${ }^{d^{*}}$}

${ }^{a}$ Univ. Rennes, Ecole Nationale Supérieure de Chimie de Rennes, CNRS, ISCR - UMR6226, F-35000 Rennes, France

${ }^{b}$ Dunarea de Jos University, Faculty of Food Science and Engineering, 47 Domneasca St., 800008 Galati, Romania

c"Vasile Alecsandri" University of Bacau, Faculty of Engineering, Department of Chemical and Food Engineering, 157 Calea Marasesti, 600115 Bacau, Romania

${ }^{d}$ Université Clermont Auvergne, CNRS, Sigma Clermont, Institut Pascal. F-63000, Clermont-Ferrand, France

*Corresponding Authors:

Prof. Lidia Favier

Ecole Nationale Supérieure de Chimie de Rennes, CNRS, UMR 6226, 11 Allée de Beaulieu CS 50837, 35708 Rennes Cedex 7, France.

Tel.: +33 233238135; Fax: +33 223238120

E-mail: lidia.favier@ensc-rennes.fr

Prof. Christophe Vial

Institut Pascal, axe GePEB, Polytech Clermont-Ferrand, 2 avenue Blaise Pascal - TSA 60206 - CS 60026 - F-63178 Aubière Cedex, France

E-mail: christophe.vial@uca.fr

Prof. Gabriela Bahrim

Dunarea de Jos University, Faculty of Food Science and Engineering, 47 Domneasca St., 800008 Galati, Romania

Tel.: +40 336130177; Fax: +40 236460165

E-mail: gbahrim@ugal.ro 


\title{
Graphical abstract
}

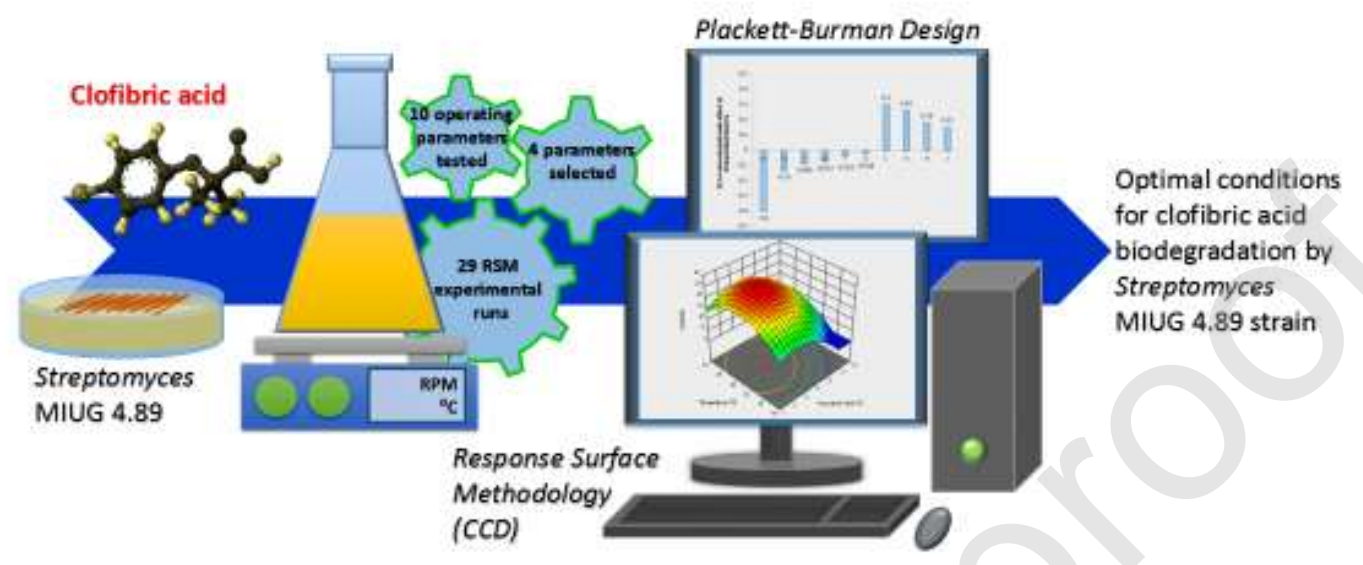

\begin{abstract}
Clofibric acid, the main pharmacologically-active metabolite of pharmaceutical products used as antilipaemic agent has received, in last years, an increased interest because of its wellknown recalcitrance to biodegradation and its high persistence in the aquatic environment. This molecule passes unchanged or poorly transformed in wastewater treatment plants. An indigenous strain of Streptomyces, named MIUG 4.89 was previously selected, exhibited the ability to favor clofibric acid biodegradation within submerged cultivation in controlled biotechnological conditions. Thus, in order to enhance the biodegradation of this refractory molecule, mathematical modeling and statistical optimization designs associated to PlackettBurman Design and Response Surface Methodology were used to evaluate and optimize the effects of different major culture conditions of this bacterial isolate. According to the results, under optimized culture conditions $\left(5 \mathrm{~g} \mathrm{~L}^{-1}\right.$ glucose, inoculation level $4.7 \%, 27.5^{\circ} \mathrm{C}$ and 20 days of incubation) the strain Streptomyces MIUG 4.89 exhibited a successful removal of clofibric acid with a biodegradation yield of 54\%, which is in agreement with model
\end{abstract}


prediction. Thus, under optimized conditions, the removal yield was enhanced, which is very promising accounting for the refractory character of this water pollutant.

Keywords: Clofibric acid, Streptomyces, Biodegradation, Plackett-Burman Design, Response Surface Methodology

\section{Introduction}

Organic contaminants in the aquatic environment have long been issues of environmental concern. While most of the first detected pollutants included dyes, pesticides and herbicides, recently, pharmaceuticals have received much attention because of on their toxic effects on biological systems and ecosystems, even at minute concentrations of a few $\mathrm{ng} \mathrm{L}^{-1}$ (Kummerer, 2010; Grigoras et al., 2020). These compounds are considered as emergent environmental contaminants and exhibit moderate to high persistence to environmental degradation in correlation with their chemical structure and toxicity. It is important to notice the important environmental impact of the continuous release of pharmaceuticals into the aquatic system posing a serious ecotoxicological risk for the aquatic wildlife (Popa Ungureanu et al., 2018, 2015; Harja et al., 2020). To date, the wastewater treatment plants (WWTPs) are considered as one of the major sources of contamination of natural water bodies (Yehya et al., 2020). Indeed, the conventional wastewater process based on the use of activated sludge was not designed to guarantee the removal of such molecules and numerous studies reported that some of these molecules pass unchanged or poorly transformed into aquatic system.

For example, clofibric acid (CLA), the main pharmacologically bioactive metabolite of the blood lipid-regulating pharmaceuticals clofibrate, etofibrate and etofyllinclofibrate, was recognized, in recent years, as one of the most persistent drugs metabolite detected in the aquatic environment (Hemidouche et al., 2018; Matamoros et al., 2008; Popa Ungureanu et al., 2016; Sescu et al., 2020). This molecule was frequently reported in numerous environmental monitoring studies, because of its recalcitrance to conventional WWTPs process. The environmental issue related to CLA is due to its high persistence (several years) into environment and also to its suspected endocrine disruptor effect, since it was reported to interfere with the synthesis of cholesterol (Khetan and Collins, 2007).

Thus, it became essential to optimize the current water treatment technologies or to develop new ones in order to prevent aquatic environmental contamination with this emergent organic pollutant (Favier et al., 2016; Yehya et al., 2015). Different physico- 
chemical technics, such as ozonation or adsorption with activated carbon were investigated in the last years to improve the performances of elimination of pharmaceuticals from wastewater effluents. However, their major drawbacks are the excessive cost which are associated to ozone treatment or the regeneration of activated carbon and also, the possibility of generation of oxidation byproducts having equal or higher toxicity than the parent compound (Torresi et al., 2019). Moreover, other studies reported that tertiary treatments (i.e. advanced the advanced oxidation (AOP), ultrafiltration and nanofiltration) are necessary to be considered to enhance the removal of these pollutants and the quality of treated effluents. However, these processes are economically unfeasible due to their operating costs and for the AOP pose a new environmental problem because of the high ecotoxicity of reaction intermediates generated during these processes (Garcia-Galan et al., 2020). Thus, for all these reasons to date, bioremediation techniques based on the use of microorganisms and/or plants to degrade organic pollutants are considered as promising alternatives to explore and received an increased attention of scientists because of their cost-effectiveness and environmental safety (Prpich and Daugulis, 2005; Mohanty and Jena, 2019).

In this context, in recent years, the degradation of this molecule by white-rot fungi has received a great interest because they are considered as one of the promising groups of organisms suitable for the remediation of pharmaceutic compounds due to their ligninolytic enzyme system (Marco-Urrea et al., 2009; Ungureanu et al., 2015a). However, several reports also provide evidence that different species belonging to the genus Streptomyces, the main group of bacteria present in soil and sediments, are able to degrade a wide range of organic and inorganic toxic compounds (Polti et al., 2014; Ravel et al., 1998; Taylor et al., 2014) emphasizing the interesting potential of these bacteria for bioremediation purposes. One strain belonging to the genus Streptomyces, named MIUG 4.89, was previously selected by Popa Ungureanu et al. (2016) for its ability to promote clofibric acid biodegradation (up to $35 \%$ ) during cultivation in submerged system under controlled biotechnological conditions at an initial clofibric acid concentration of $0.2 \mathrm{mg} \mathrm{L}^{-1}$.

In a bioremediation process the pollutant elimination efficiency could be affected by different parameters, such as the pollution load, nutritional conditions, and the physicochemical factors. Hence, it is of key importance to evaluate their effects and to optimize the most determinant ones in order to find the appropriate biodegradation conditions for pollutant elimination. The optimization of fermentation conditions particularly nutritional and environmental ones are therefore, of utmost importance in a biodegradation process to enhance its performance. To date, statistical methods are considered to be effective and 
powerful tools for rapidly screening of key factors from a multivariable system to optimize fermentation conditions of microorganisms (Majumder and Goyal, 2008; Tanyildizi et al., 2005) with a reduced number of experiments.

Plackett-Burman Designs (Pan et al., 2008; Plackett and Burman, 1946) and Response Surface Methodology (RSM) have been successfully used for multivariable optimization studies in several biotechnological, environmental and chemical processes (Beg et al., 2003; De Coninck et al., 2000; Elibol, 2004; Lai et al., 2003; Puri et al., 2002). RSM consists in a collection of statistical techniques for designing experiments and building models evaluating the interactive effects between factors and searching for the optimum conditions for desirable responses (Lee et al., 2003; Li et al., 2002) satisfying the process requirements.

In this framework, the aim of this work is, therefore, to enhance the biodegradation efficiency of CLA by the selected strain Streptomyces MIUG 4.89 through the optimization of the nutritional and environmental factors using mathematical modeling and statistical analysis techniques associated to design of experiments methodology, which includes screening by Plackett-Burman Designs and Response Surface Methodology for optimization purpose. This is the first study describing a successful optimization of culture conditions for the biodegradation of this drug of environmental concern due to its persistence in the aquatic environment and its resistance to conventional wastewater treatment.

\section{Materials and methods}

\section{Chemicals}

Clofibric acid the target pollutant investigated in this work $\left(\mathrm{C}_{10} \mathrm{H}_{11} \mathrm{ClO}_{3}\right.$, CAS number 882-09-7) belongs to lipid regulator therapeutic class. Its main physico-chemical properties are: molecular weight, $214.65 \mathrm{~g} \mathrm{~mol}^{-1}$; water solubility, $573 \mathrm{mg} \mathrm{L}^{-1}\left(25^{\circ} \mathrm{C}\right)$; $\mathrm{pK}_{\mathrm{a}}, 3$ and a $\log$ kow of 2.57 (Zhang et al., 2012). CLA, methanol (HPLC grade) and all chemicals used for the culture media formulation were obtained from Sigma-Aldrich (St. Louis, MO, USA) and were of analytical grade purity (> 99\%).

\section{Biodegradation experiments}

The biodegradation experiments were performed under non-acclimated conditions with the strain Streptomyces MIUG 4.89 obtained from the Microbial Cultures Collection (acronym MIUG) of the Bioaliment Research Center of the "Dunarea de Jos" University of Galati, Romania (Faculty of Food Science and Engineering). The pure culture was kept at $4^{\circ} \mathrm{C}$ on Gauze's synthetic agar medium as described previously by Atlas (2010). Gauze's 
medium, consisting of starch, $20 \mathrm{~g}$; $\mathrm{K}_{2} \mathrm{HPO}_{4}, 0.5 \mathrm{~g} ; \mathrm{MgSO}_{4} \cdot 7 \mathrm{H}_{2} \mathrm{O}, 0.5 \mathrm{~g} ; \mathrm{KNO}_{3}, 1.0 \mathrm{~g} ; \mathrm{NaCl}$, $0.5 \mathrm{~g} ; \mathrm{FeSO}_{4} \cdot 7 \mathrm{H}_{2} \mathrm{O}, 0.01 \mathrm{~g}$ per liter of distilled water was used for biomass propagation. Medium $p \mathrm{H}$ was adjusted to 7.2 after sterilization. Cultivation took place in Erlenmeyer flasks of $250 \mathrm{~mL}$ containing $50 \mathrm{~mL}$ of medium. Cultures were incubated at a temperature of $25^{\circ} \mathrm{C}$ on an orbital shaker (SI-300R Incubator Shaker; Jeio Tech, Korea) at $150 \mathrm{rpm}$ for $72 \mathrm{~h}$ prior each degradation test.

All biodegradation assays were carried out in basal liquid medium (Hopwood, 1967). Its non-optimized composition includes ( $\mathrm{g} / \mathrm{L}$ of distilled water): $\mathrm{L}-$ aspargine, $0.5 ; \mathrm{K}_{2} \mathrm{HPO}_{4}$, $0.5 ; \mathrm{MgSO}_{4} \cdot 7 \mathrm{H}_{2} \mathrm{O}, 0.20 ; \mathrm{FeSO}_{4} \cdot 7 \mathrm{H}_{2} \mathrm{O}, 0.01$. They were carried out in the batch mode under aerobic conditions and were conducted under aseptic conditions. Samples were harvested at different incubation times and quantitative determinations were performed to measure the biomass concentrations (dry weight) and the residual pollutant content; the aim was to investigate cell growth and the removal yield of the target pollutant. Several cultivation parameters which could influence the degradation ability of Streptomyces MIUG 4.89 were investigated in this work. The considered factors were: the initial pollutant concentration, the concentrations of nitrogen and glucose, inoculum concentration, inoculum age, initial $p \mathrm{H}$, temperature, agitation rate, incubation time and the culture volume. Their respective effects on the CLA biodegradation yield was analyzed and optimized using the "design of experiments" methodology detailed later in this paper which includes a screening PlackettBurman Design and Response Surface Methodology.

Additional information about the different steps considered for experimental design and bioprocess optimization conditions are given in Fig.1.

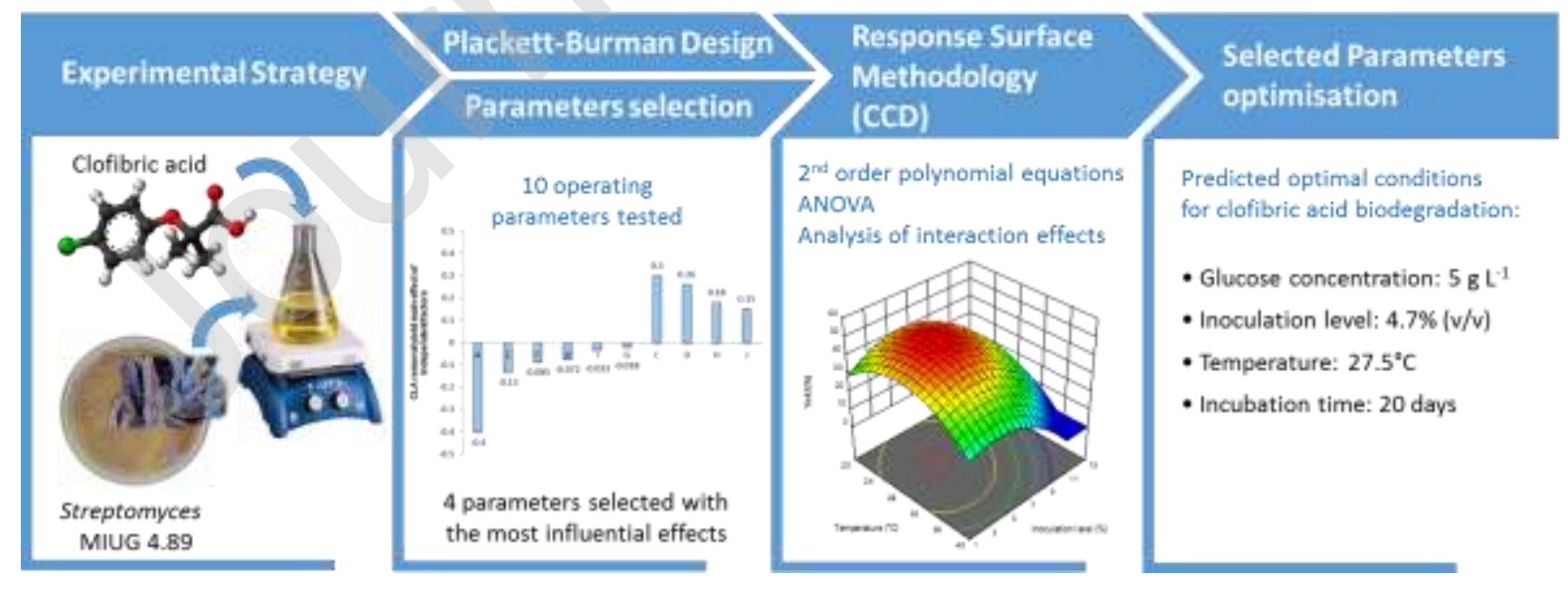

Fig. 1 Schematic presentation of the developed approach used for the analysis bioprocess conditions and optimization. 


\section{Biomass determination}

Biomass concentration was determined by the dry weight measurement and expressed in $\mathrm{g} \mathrm{L}^{-1}$. Cell biomass was collected by vacuum filtering using pre-weighed membranes (0.45 $\mu \mathrm{m}$, cellulose acetate; Sartorius Stedim Biotech, GmbH, Germany), then washed twice with distilled water; finally, filters were dried at $100^{\circ} \mathrm{C}$ for $24 \mathrm{~h}$.

\section{HPLC analysis}

Culture samples were centrifuged for 10 minutes at 10,000 rpm (Heltich Universal $320 \mathrm{R}$ ) and the obtained supernatants were filtered through a $0.2 \mu \mathrm{m}$ pore-size polypropylene syringe filters (PALL Life Science, New York, USA) to remove the biomass. Pollutant concentration was determined by high-performance liquid chromatography (HPLC, Agilent 1200 Series, Santa Clara, CA, USA). This system was equipped with a photodiode array (PDA) detector. For analyte separation, a reverse phase BDS Hypersil C18 column (250 $\mathrm{mm} \times 4.6 \mathrm{~mm}$, with particle size $5 \mu \mathrm{m}$ ) was used. The mobile phase consisted in a mixture of $70 \%$ methanol and 30\% (v/v) ultrapure water acidified with $0.1 \%(\mathrm{v} / \mathrm{v})$ acetic acid. Analysis was performed under isocratic mode at a flow rate of $0.7 \mathrm{~mL} \mathrm{~min}^{-1}$. Column temperature was set at $40^{\circ} \mathrm{C}$ and the injected volume was $50 \mu \mathrm{L}$. The detection wavelength was $230 \mathrm{~nm}$. Under these conditions the retention time of CLA was 14 minutes and the instrumental limit of quantification (LOQ) was lower than $0.05 \mathrm{mg} \mathrm{L}^{-1}$. CLA concentration (expressed in $\mathrm{mg} \mathrm{L}^{-}$

${ }^{1}$ ) was calculated using an external calibration curve, as previously described by Kadmi et al. (2017). Calibration was performed in the range of $0-10 \mathrm{mg} \mathrm{L}^{-1}$ by the use of standard solutions with a known analyte concentration. The identification of the CLA biodegradation intermediates was performed consudering the same analytical strategy with one developed for quantification of the target molecule. Analytical standards of $5 \mathrm{mg} / \mathrm{L}$ were used for this purpose. The percentage of CLA degradation (biodegradation yield or removal efficiency) was calculated as follows:

$R_{\%}=\left(\left(C_{0}-C_{f}\right) / C_{0}\right) \cdot 100(1)$

where $C_{0}$ and $C_{f}$ were CLA concentrations $\left(\mathrm{mg} \mathrm{L}^{-1}\right)$ measured after culture inoculation and at the end of the incubation time, respectively.

\section{Experimental design and data analysis}


Response surface analysis is a statistical methodology considered as an effective tool for process optimization problems (Ambasha and Sillanpaa, 2011; Bankar and Singhal, 2010; Sonwani et al., 2019). However, such method is generally can be applied only to a limited number of factors, usually four or less. In the present work, a Plackett-Burman Design (PBD) was used for screening purpose, so as to determine the three or four most influencing factors, and then a Central Composite Design (CCD) was defined to optimize the biotechnological conditions of biodegradation of CLA.

\section{Plackett-Burman Design}

For the identification of the most important independent variables with significant influence on CLA removal, a rapid multifactorial screening using Plackett-Burman Design (PDB) was performed. PBD is recognized as a very versatile and interesting screening method to select the most important process parameters among various factors involved in the process (Popa Ungureanu et al., 2015b).

Ten independent variables (physical and nutritional parameters) considered to play an important role in a biodegradation process were evaluated using PBD and a first-order polynomial model:

$Y=\beta_{0}+\sum \beta_{i} \chi_{i}(2)$

where $Y$ is the predicted response (clofibric acid biodegradation yield), $\beta_{0}$ and $\beta_{i}$ are the coefficients of the model and $\chi_{i}$ is the level of the $i^{\text {th }}$ independent variable. The ten independent variables, denoted by letters $A$ to $J$ in Table 1 were: the pollutant concentration $(A)$, nitrogen concentration through yeast extract which is used to control nitrogen content $(B)$, glucose concentration $(C)$, inoculum concentration $(D)$, inoculum age $(E)$, culture volume $(F), p \mathrm{H}(G)$, temperature $(H)$, agitation rate $(I)$, and incubation time $(J)$.

Table 1. Independent variables and their levels tested in a Plackett-Burman Design for the CLA biodegradation by Streptomyces MIUG 4.89

\begin{tabular}{llllc}
\hline Factors & Unit & Symbol & $\begin{array}{l}\text { Levels }\left(\chi_{\mathrm{i}}\right) \\
\text { Low }(-1)\end{array}$ & High $(+1)$ \\
\hline Clofibric acid & $\mathrm{mg} \mathrm{L}^{-1}$ & $A$ & 0.2 & 8.0 \\
Yeast extract & $\mathrm{g} \mathrm{L}^{-1}$ & $B$ & 1.0 & 3.0
\end{tabular}




\begin{tabular}{lllll} 
Glucose & $\mathrm{g} \mathrm{L}^{-1}$ & $C$ & 3.5 & 10.5 \\
Inoculation level & $\%(\mathrm{v} / \mathrm{v})$ & $D$ & 4.0 & 10.0 \\
Inoculum age & $\mathrm{h}$ & $E$ & 24.0 & 72.0 \\
Culture volume & $\mathrm{mL}$ & $F$ & 50.0 & 250.0 \\
$p \mathrm{H}$ & & $G$ & 5.0 & 7.0 \\
Temperature & ${ }^{\circ} \mathrm{C}$ & $H$ & 25.0 & 35.0 \\
Agitation rate & $\mathrm{rpm}$ & $I$ & 100.0 & 200.0 \\
Incubation time & days & $J$ & 10.0 & 20.0 \\
\hline
\end{tabular}

They were assessed in order to establish which variables have a significant effect on the CLA biotransformation yield as the unique response $Y$. According to Plackett-Burman Design methodology, each factor was tested at two levels, considered as coded low (-1) and high (+1) level, respectively. It must be pointed out that the levels used in the PBD of experiments were defined according to the results obtained in a preliminary unpublished work. The actual and coded levels of the experimental design (variables and tested range) used in this work are summarized in Table 2.

All assays were performed in triplicate and the averages of the results were taken as response values. Factors with a confidence level higher than 95\% ( $p$-value, $p<0.05$ ) were considered as significant for the pollutant biodegradation and only the variables with a positive influence on clofibric acid degradation were used for further optimization by Response Surface Methodology (RSM).

\section{Central Composite Design of experiments}

Generally, PBD is employed as the first step to screen significant factors and is followed by RSM, which often consists in an optimization design of experiments strategy usually based on a Central Composite Design (Fu et al., 2009; Gao et al., 2009). In this work, after the selection of the most significant factors, Response Surface Methodology was used for optimization purposed so as to maximize the response. Factorial Central Composite Design (CCD) and RSM were used to obtain more information about the significant effects, particularly their mutual interactions, which exhibit a positive influence on CLA biodegradation, and to determine their optimal values which maximize the degradation yield of CLA. Four independent parameters were deduced from PDB as the most significant for the response (glucose concentration $(C)$, inoculum concentration $(D)$, temperature $(H)$ and incubation time $(J)$ were evaluated by mathematical optimization and statistical analysis. 
Each significant parameter was evaluated at five levels consisting in the coded levels -1 and +1 of each factor, two star points $(-\alpha,+\alpha)$ per factor with $\alpha=2^{n / 4}=2$, as $n$ is the number of parameters ( $n=4$ in this work), and the level coded 0 (i.e. the central point), to estimate experimental error. Experimental levels were determined by varying the considered parameters above and below the central point, as shown in Table 3. A factorial $2^{n} \mathrm{CCD}$ design was applied, so that a set of 29 runs including 5 replications of the central point was defined, which ensured rotatability of the design with $\alpha=2$.

CLA elimination yield was analyzed using a second-order polynomial equation:

$$
\begin{aligned}
& Y=\beta_{0}+\beta_{1} C+\beta_{2} D+\beta_{3} H+\beta_{4} J+\beta_{12} C D+\beta_{13} C H+\beta_{14} C J+\beta_{23} D H+ \\
& +\beta_{24} D J+\beta_{34} H J+\beta_{11} C^{2}+\beta_{22} D^{2}+\beta_{33} H^{2}+\beta_{44} J^{2}
\end{aligned}
$$

where $Y$ is the predicted response (CLA biodegradation yield or removal efficiency expressed in \%), the letters $C, D, H, J$ are the codes of the independent variables (Table 2) determined previously as the most significant for the biodegradation process; $\beta_{i}(i>0)$ are the coefficients of the main effects; $\beta_{i i}$ are the coefficients of the quadratic main effects, while $\beta_{i j}(i \neq j)$ are the interaction coefficients, while $\beta_{0}$ represents the average of the responses. Experimental results were fitted using multilinear regression procedure, and ANalysis Of VAriance (ANOVA) was applied to assess the significance of the predictors, as described in the next section.

Table 2. Coded and actual range of independent variables used in the Central Composite Design (CCD)

\section{Independent variables}

Concentration of glucose $\left(\mathrm{g} \mathrm{L}^{-1}\right)$
Inoculation level $(\% \mathrm{v} / \mathrm{v})$
Temperature $\left({ }^{\circ} \mathrm{C}\right)$
Incubation time (days)

Concentration of glucose $\left(\mathrm{g} \mathrm{L}^{-1}\right)$

\section{Statistical analysis}

\section{Coded levels}

\begin{tabular}{llllll}
\hline Symbol & $\boldsymbol{- \alpha}$ & $\mathbf{- 1}$ & $\mathbf{0}$ & $\mathbf{+ 1}$ & $+\boldsymbol{\alpha}$ \\
$C$ & 2.0 & 4.5 & 7.0 & 9.5 & 12.0 \\
$D$ & 1.0 & 4.0 & 7.0 & 10.0 & 13.0 \\
$H$ & 20.0 & 25.0 & 30.0 & 35.0 & 40.0 \\
$J$ & 5.0 & 10.0 & 15.0 & 20.0 & 25.0 \\
\hline
\end{tabular}


ANOVA was used to evaluate the statistical analysis of the model. This analysis consisted in Fisher's $F$-test, its associated probability $(F)$, the $p$-value of the test $(p)$, and the determination coefficient $\left(R^{2}\right)$ estimating the goodness-of-fit of the regression model (PopaUngureanu et al., 2015). Design Expert software (version 8.0., State-Ease, Inc., Minneapolis, MN, USA) was used for the experiments design, data analysis, quadratic model building, statistical analysis, and for the response surface contour plots of the predicted responses. For optimization purpose, the objective was to maximize the unique response, the CLA removal yield.

\section{Results and discussion}

Screening of the most significant parameters influencing CLA removal using the Plackett-

\section{Burman Design}

The effect of the considered ten factors (nutritional and culture conditions) on the removal of the target molecule were firstly statistically studied by using PBD in order to select the most significant parameters playing a positive effect on CLA biodegradation. The matrix considered for screening step and the experimental results for the response (CLA removal yield) are displayed in Table 3.

Table 3. Plackett-Burman Design of the main factors (in coded levels) for the selection of most significant parameters for CLA biodegradation by Streptomyces MIUG 4.89

\begin{tabular}{llllllllllll}
\hline \multirow{2}{*}{ Run } & \multicolumn{1}{c}{ Factor (coded levels) } & & & & & \multirow{2}{*}{ Removal yield (\%) } \\
\cline { 2 - 7 } & $\boldsymbol{A}$ & $\boldsymbol{B}$ & $\boldsymbol{C}$ & $\boldsymbol{D}$ & $\boldsymbol{E}$ & $\boldsymbol{F}$ & $\boldsymbol{G}$ & $\boldsymbol{H}$ & $\boldsymbol{I}$ & $\boldsymbol{J}$ & \\
\hline 1 & -1 & -1 & -1 & -1 & -1 & -1 & -1 & -1 & -1 & -1 & 7 \\
2 & -1 & +1 & +1 & -1 & -1 & +1 & +1 & +1 & -1 & -1 & 12 \\
3 & +1 & +1 & -1 & -1 & +1 & -1 & -1 & +1 & +1 & -1 & 0 \\
4 & +1 & -1 & -1 & +1 & -1 & +1 & +1 & +1 & +1 & -1 & 0 \\
5 & +1 & +1 & +1 & +1 & +1 & +1 & -1 & -1 & -1 & -1 & 0 \\
6 & -1 & +1 & -1 & -1 & +1 & +1 & +1 & -1 & +1 & +1 & 8 \\
7 & -1 & -1 & +1 & +1 & +1 & -1 & +1 & -1 & +1 & -1 & 15 \\
8 & -1 & +1 & +1 & +1 & -1 & -1 & -1 & +1 & +1 & +1 & 16 \\
9 & -1 & -1 & -1 & +1 & +1 & +1 & -1 & +1 & -1 & +1 & 18 \\
10 & +1 & -1 & +1 & -1 & +1 & -1 & +1 & +1 & -1 & +1 & 0 \\
\hline
\end{tabular}




\begin{tabular}{lllllllllllll}
\hline 11 & +1 & -1 & +1 & -1 & -1 & +1 & -1 & -1 & +1 & +1 & 0 & \\
\hline
\end{tabular}

Data analysis from Table 3 indicates that the response lies in the range $0-18 \%$ for the considered 11 runs. Figure 2 displays the statistical analysis of the results. In this figure, the positive or the negative sign of the coefficient of a considered variable shows whether an increase in the level of this factor increases or inhibits the pollutant removal efficiency. It is important to note that the greater the observed magnitude, the higher the significance of this variable. The results in Fig. 2 suggest first that an optimization step is necessary to enhance the elimination of the target molecule. In addition, according to the statistical analysis, it can be observed on the one hand that the following factors, namely initial pollutant concentration $(A)$, inoculum age $(E)$, culture volume $(F)$, yeast extract concentration $(B)$, agitation rate $(I)$ and initial $p \mathrm{H}(G)$, displayed a negative effect on CLA removal, whereas the other parameters are found to exhibit a positive influence on the biodegradation of the pollutant. On the other hand, the obtained results show that, in the case of CLA biodegradation by Streptomyces MIUG 4.89, the factors such as culture volume $(F)$, yeast extract concentration $(B)$, agitation rate $(I)$ and $p \mathrm{H}(G)$ appear to have no significant effect on pollutant elimination for the considered range of variation (Table 2). In practice, the supplementary carbon source (glucose) $(C)$ and the inoculation level $(D)$ exhibit the highest positive effect in the process of CLA biodegradation. Moreover, it can be observed that the increase in initial pollutant concentration displays the highest negative impact on pollutant elimination.

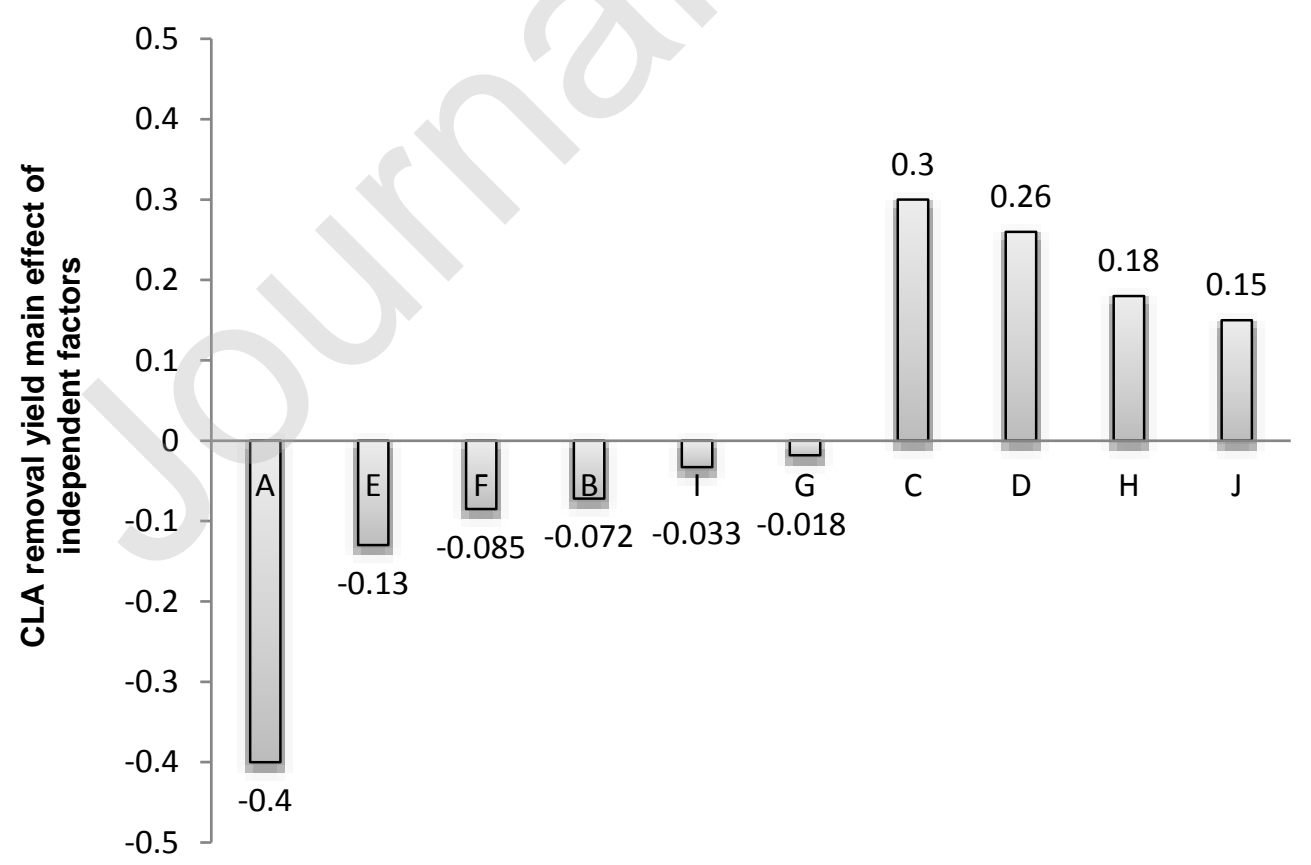


Fig. 2 Effects of the considered independent factors (positive and negative) on CLA biodegradation yield by Streptomyces MIUG 4.89 screened with a Plackett-Burman design

The decrease in the elimination efficiency with the increase of pollutant concentration (up to $8 \mathrm{mg} \mathrm{L}^{-1}$ ) may be due to its toxicity. This result is in agreement with literature data reporting that cell growth was generally favored at the lowest pollutant concentration which, as a consequence; was supposed to enhance the removal efficiency (Rigas et al., 2005). Thus, for further experiments, in order to reduce the number of parameters to be optimized, we fixed this parameter at its lowest value (according to the experimental design) to better approach the concentration usually found in wastewater effluents for this molecule (Hemidouche et al., 2018; Klavarioti et al., 2009; Salgado et al., 2012).

Finally, the variables considered to have positive influence on CLA biodegradation were also analyzed using ANOVA through a joint test. The $F$-test was employed to evaluate the significance of the regression coefficients of these parameters. Only the factors with a pvalue, $p<0.05$, were considered significant in the biodegradation process $(95 \%$ confidence level). The obtained results of the ANOVA are summarized in Table 4. According to this table, the four variables denoted glucose concentration $(C)$, inoculation level $(D)$, temperature $(H)$, and cultivation time $(J)$ were found to be statistically significant for the pollutant biodegradation and must be considered for further optimization studies to estimate the maximum of the response variable.

Table 4. Analysis of variance (ANOVA) of the variables exhibiting a positive effect on the CLA biodegradation efficiency (DF: degree of freedom)

\begin{tabular}{llllll}
\hline Source & $\begin{array}{l}\text { Sum of } \\
\text { squares }\end{array}$ & DF & $\begin{array}{l}\text { Mean } \\
\text { square }\end{array}$ & $\boldsymbol{F}$ & $\boldsymbol{p}$-value \\
& 555.70 & 5 & 111.14 & 27.06 & 0.0005 \\
Model & 8.84 & 1 & 8.84 & 2.15 & 0.0193 \\
$C$ - glucose concentration $\left(\mathrm{g} \mathrm{L}^{-1}\right)$ & 41.44 & 1 & 41.44 & 10.09 & 0.0192 \\
$D$ - inoculation level $(\%)$ & 22.14 & 1 & 22.14 & 5.39 & 0.0059 \\
$H$ - temperature $\left({ }^{\circ} \mathrm{C}\right)$ & 5.74 & 1 & 5.74 & 1.40 & 0.0281 \\
$J$ - cultivation time $(\mathrm{h})$ & 24.64 & 6 & 4.11 & & \\
Residual errors & 580.35 & 11 & & &
\end{tabular}


Mathematical modeling for the optimization of biodegradation process

Based on the previous results from PBD, only four parameters were considered as the factors with positive influence on the biodegradation process with the Streptomyces MIUG 4.89 strain and were further optimized using CCD. Each variable was investigated at five coded levels $(-\alpha,-1,0,+1,+\alpha)$. The set of 29 runs of the CCD is presented in Table 5 which displays all the combinations of the factors. Table 5 also summarizes the experimental results obtained for CLA biodegradation efficiency for each tested condition.

Table 5. Design matrix of the optimization design (CCD) for the most significant coded factors, with the experimental and predicted values of the responses

\begin{tabular}{|c|c|c|c|c|c|c|}
\hline \multirow[t]{2}{*}{ Runs } & \multirow{2}{*}{$\begin{array}{l}\text { Glucose } \\
\text { concentration } \\
(\mathrm{g} / \mathrm{L})\end{array}$} & \multirow{2}{*}{$\begin{array}{l}\text { Inoculation } \\
\text { level } \\
(\%)\end{array}$} & \multirow{2}{*}{$\begin{array}{l}\text { Temperature } \\
\left({ }^{\circ} \mathrm{C}\right)\end{array}$} & \multirow{2}{*}{$\begin{array}{l}\text { Time } \\
\text { (days) }\end{array}$} & \multicolumn{2}{|c|}{$\begin{array}{l}\text { Biodegradation yield } \\
(\%)\end{array}$} \\
\hline & & & & & Experimental & Predicted \\
\hline 1 & -1 & -1 & -1 & -1 & 19 & 19.2 \\
\hline 2 & -1 & -1 & 1 & 1 & 44 & 43.7 \\
\hline 3 & -1 & 1 & -1 & -1 & 26 & 25.5 \\
\hline 4 & 1 & -1 & -1 & 1 & 27 & 27.5 \\
\hline 5 & -1 & 1 & 1 & 1 & 22 & 23.0 \\
\hline 6 & 1 & 1 & 1 & -1 & 36 & 36.2 \\
\hline 7 & 1 & -1 & 1 & -1 & 27 & 26.3 \\
\hline 8 & 1 & 1 & -1 & 1 & 23 & 25.3 \\
\hline 9 & 1 & -1 & 1 & 1 & 25 & 27.2 \\
\hline 10 & -1 & 1 & -1 & 1 & 38 & 38.3 \\
\hline 11 & 1 & 1 & 1 & 1 & 18 & 17.5 \\
\hline 12 & 0 & 0 & 0 & 0 & 46 & 43.4 \\
\hline 13 & 0 & 0 & 0 & 0 & 42 & 43.4 \\
\hline 14 & 0 & 0 & 0 & 0 & 42 & 43.4 \\
\hline 15 & 0 & 0 & 0 & 0 & 43 & 43.4 \\
\hline 16 & 0 & 0 & 0 & 0 & 44 & 43.4 \\
\hline 17 & -2 & 0 & 0 & 0 & 35 & 35.3 \\
\hline 18 & 2 & 0 & 0 & 0 & 26 & 24.3 \\
\hline 19 & 0 & -2 & 0 & 0 & 27 & 26.0 \\
\hline 20 & 0 & 2 & 0 & 0 & 23 & 22.7 \\
\hline
\end{tabular}




\begin{tabular}{lllllll}
21 & 0 & 0 & -2 & 0 & 30 & 28.2 \\
22 & 0 & 0 & 2 & 0 & 25 & 25.5 \\
23 & 0 & 0 & 0 & -2 & 24 & 25.5 \\
24 & 0 & 0 & 0 & 2 & 42 & 39.2 \\
25 & 1 & 1 & -1 & -1 & 31 & 31.0 \\
26 & 1 & -1 & -1 & -1 & 13 & 13.7 \\
27 & -1 & -1 & 1 & -1 & 25 & 24.3 \\
28 & -1 & -1 & -1 & 1 & 50 & 51.5 \\
29 & -1 & 1 & 1 & -1 & 24 & 23.2 \\
\hline
\end{tabular}

In Table 5, the highest removal yield is close to $50 \%$ and this value is approached by treatment 28 . In addition, several treatments corresponding to runs $2,12,13,14,15$, and 16 , approach the second highest value, about $44 \%$. It must be mentioned that runs $12-16$ correspond to the replications of the central point, but not run 2, which highlights the presence of a maximum value in the range studied $[-1 ;+1]^{4}$.

Then, CDD enables the development of a mathematical equation from which the response can be estimated as a function of the predictors (Im et al. 2012). For the calculation of maximum removal yield, the quadratic polynomial model of eq. 2 was used and the regression analysis of the results was performed to check the statistical significance of the predictors. Table 6 gives the obtained results for ANOVA applied to the model of the CLA removal yield. This highlights the significance of the model $(p<0.0001)$. For example, Zhang et al. (2009) reported a $p$-value below 0.001 for a very significant model, while a significant model had a $p$-value below 0.01, and an almost significant model exhibits only $0.01<p<0.05$. The obtained values of the determination coefficient $\left(R^{2}\right)$ and of the adjusted determination coefficient $\left(\operatorname{adj} R^{2}\right)$ were also considered as satisfactory $(0.983$ and 0.966 , respectively) confirming the significance of the polynomial equation. $R^{2}$ indicates that the considered model could explain up to $98 \%$ of variability of the biodegradation yield, as the obtained value is very close to 1 indicating an accurate prediction of the response by the developed model.

Table 6. ANOVA results for the response surface second order model (DF: degrees of freedom)

\begin{tabular}{llllll}
\hline Source & $\begin{array}{l}\text { Sum of } \\
\text { squares }\end{array}$ & DF & $\begin{array}{l}\text { Mean } \\
\text { square }\end{array}$ & F & p-value \\
\hline
\end{tabular}




\begin{tabular}{|c|c|c|c|c|c|}
\hline Model & 2626.33 & 14 & 187.59 & 57.68 & $<0.0001$ \\
\hline$C$-glucose & 181.50 & 1 & 181.50 & 55.81 & $<0.0001$ \\
\hline$D$ - inoculation & 16.67 & 1 & 16.67 & 5.12 & 0.0400 \\
\hline$H$ - temperature & 10.67 & 1 & 10.67 & 3.28 & 0.0916 \\
\hline$J$ - incubation & 280.17 & 1 & 280.17 & 86.14 & $<0.0001$ \\
\hline$C D$ & 121.00 & 1 & 121.00 & 37.20 & $<0.0001$ \\
\hline $\mathrm{CH}$ & 56.25 & 1 & 56.25 & 17.30 & 0.0010 \\
\hline$C J$ & 342.25 & 1 & 342.25 & 105.23 & $<0.0001$ \\
\hline$D H$ & 56.25 & 1 & 56.25 & 17.30 & 0.0010 \\
\hline$D J$ & 380.25 & 1 & 380.25 & 116.91 & $<0.0001$ \\
\hline$H J$ & 169.00 & 1 & 169.00 & 51.96 & $<0.0001$ \\
\hline$A^{2}$ & 298.47 & 1 & 298.47 & 91.77 & $<0.0001$ \\
\hline$B^{2}$ & 589.52 & 1 & 589.52 & 181.26 & $<0.0001$ \\
\hline$C^{2}$ & 445.06 & 1 & 445.06 & 136.84 & $<0.0001$ \\
\hline$D^{2}$ & 198.60 & 1 & 198.60 & 61.06 & $<0.0001$ \\
\hline Residual & 45.53 & 14 & 3.25 & & \\
\hline Lack-of-Fit & 34.33 & 10 & 3.43 & 1.23 & 0.4565 \\
\hline Pure Error & 11.20 & 4 & 2.80 & $R^{2}$ & 0.9830 \\
\hline \multirow[t]{3}{*}{ Total } & 2671.86 & & & Adjusted $\boldsymbol{R}^{2}$ & 0.9659 \\
\hline & & & & Predicted $\boldsymbol{R}^{2}$ & 0.9194 \\
\hline & & & & CV (\%) & 5.83 \\
\hline
\end{tabular}

$\overline{\mathrm{CV}}$ : coefficient of variation.

The low value of the coefficient of variation $(\mathrm{CV}), 5.83 \%$, confirms that the experiments performed in this work could be considered as reliable and precise. Indeed, a low value of this parameter means that the experimental tests are highly reliable (Li et al. 2009). For example, Rosales et al. (2012) indicated that a statistical model exhibits a reasonable reproducibility if the value of $\mathrm{CV}$ is not greater than $10 \%$. In addition, the lack-of-fit of the model was insignificant $(p>0.45)$, which shows that pure error and total error can be confounded. Finally, the p-value of the model, the CV value, the lack-of-fit, and all the regression and determination coefficients ensure a satisfactory adjustment of the quadratic model to experimental results (Im et al., 2012).

After this step, a second-order polynomial equation of the model was obtained: 
$Y=43.4-2.75 C-0.83 D-0.67 H+3.42 J+2.75 C D+1.87 C H-4.62 C J-$

$-1.87 D H-4.87 D J-3.25 H J-3.39 C^{2}-4.77 D^{2}-4.14 H^{2}-2.77 J^{2}$

where $Y$ is the predicted value of CLA elimination efficiency, while, $C, D, H, G$ were the coded values of the independent variables considered in this study (glucose concentration, inoculation level, temperature, and incubation time, respectively). It must be noticed from eq. 4 that the positive and negative signs of the terms indicate the positive or negative effect of each considered parameter on the response. The analysis of the regression equation showed that increasing three of the main factors $C, D, H$, the interactions $C J, D H, D J, H J$, and all quadratic terms $C^{2}, D^{2}, H^{2}$ and $J^{2}$ impairs the removal yield. On the contrary, only the main factor $J$, and the interactions $C D$ and $C H$ displayed a positive effect on the response.

The significance of each model coefficient can then be analyzed from Table 7. Among the 14 terms estimated in eq. 4, i.e. 4 linear terms or first-order effects, 6 interaction terms for two factorial interactions, and 4 quadratic terms or second-order effects, 13 predictors are shown to be significant $(p<0.05)$ and 10 are highly significant $(p<0.001)$. Among the main linear factors, only one predictor $H$ (temperature) is not significant; however, the fact that $H^{2}$ is highly significant highlights that the effect of temperature is statistically significant and clearly non-linear. Conversely, it can be observed that the linear effects of incubation time $(J)$ and glucose concentration $(C)$ are the most significant among the main linear factors $(p<0.0001)$; the fact that the $J$ coefficient is positive and highly significant implies, as expected, that yield increases first rapidly with time, and then levels off, which is accounted by the negative sign of the coefficient of $J^{2}$. Among the interactions, the interactive effect of inoculation level and incubation time $D J$ is the most significant $(p<$ 0.0001), while the several effects involving temperature $(\mathrm{CH}$ and $\mathrm{DH})$ were less significant ( $p$ $=0.001)$, probably for the reason stated above. In addition, all quadratic terms $C^{2}, B^{2}, H^{2}, J^{2}$ were highly significant $(p<0.0001)$, which means that a maximum may potentially be found for all the factors due to the parabolic shape opened downwards induced by this result. This is expected, for example, for temperature. Similarly, glucose acts as a co-substrate, and the negative sign of the coefficients of $C$ and $C^{2}$ probably means that glucose competes with CLA as a nutriment for the microorganisms. The model of eq. 4 can thus be simplified by removing only the $H$ term.

\section{Analysis of model adequacy}


Generally, it is important to check whether the statistical model derived from CCD provides predictions very close to experiments (Tzikalos et al., 2013). Thus, Figure 3 presents the agreement between experimental biodegradation yield and the corresponding predicted values using the simplified model (without $\mathrm{H}$ predictor). The experimental points are situated very close to the diagonal line, demonstrating a very good agreement between the experimental data and predictions for the CLA elimination efficiency. A model allowing a good fit between the observed and predicted data is necessary to avoid poor or ambiguous results in the optimization procedure of a response surface (Im et al., 2012) because it ensures that predictions remain close to actual data, which has been achieved in this work.

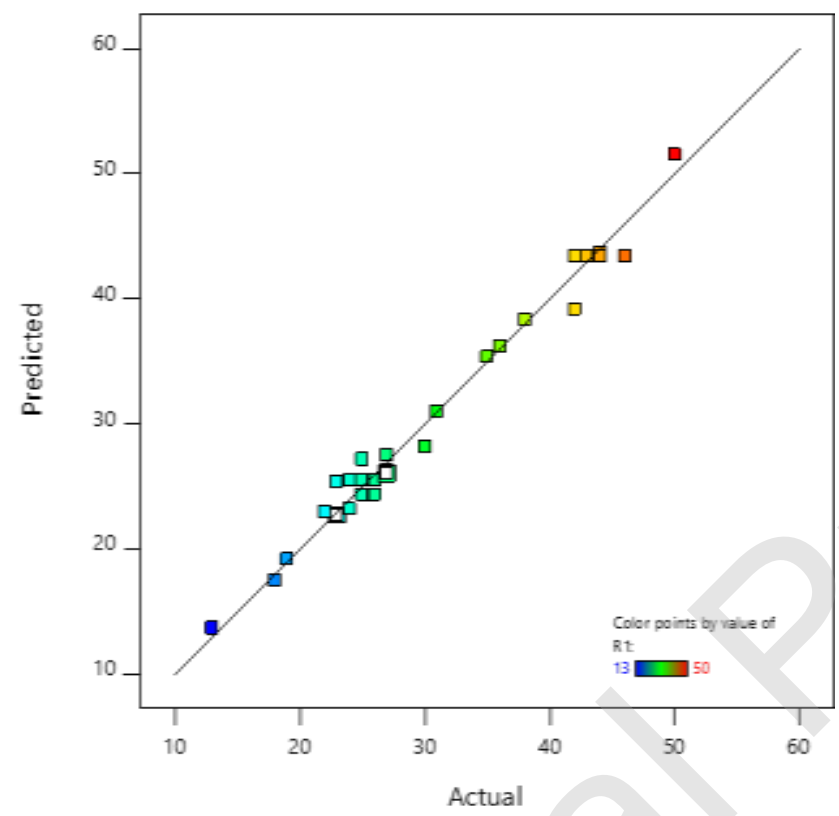

Fig. 3 Comparison between experimental results and predictions for CLA biodegradation efficiency using the second-order polynomial equation (eq. 4)

\section{Application of RSM to study the mutual interactions between the significant parameters}

In many studies, Response Surface Methodology was considered as a useful tool to predict the elimination efficiency of pollutants in different kind of environmental processes (physicochemical or biological) involving different types of independent variables and helped evaluate the interactions between these parameters (Abdessalem et al., 2008; Ambashta and Sillanpää, 2011; Dayana Priyadharshini and Bakthavatsalam, 2016).

In this work, the combined effects of the considered independent variables (i.e. glucose concentration, inoculation level, temperature and incubation time) on the response (biodegradation efficiency) were thus analyzed using this method. According to Jabeen et al. 
(2015), such strategy is considered as time effective compared to the conventional technique based on "single factor at a time experiments" explaining more accurately the effects of the different significant variables involved in an elimination process, while minimizing the number of experiments. To the best of our knowledge, such interactive work on the influence of process variable on the biodegradation of CLA had not been reported yet in the literature. A detailed presentation about the effect of interactions of the significant factors on the CLA elimination efficiency is, therefore, reported below. Response surface and contour plots were constructed by varying the considered variables according to the experimental range presented in Table 3, while the other variables were fixed in order to show the trends close to the optimum. These contour plots are graphical representations of the response surface. The obtained results are depicted in Figures 4-5.

The 3D surface plots illustrating the interaction effects of glucose concentration $(C)$ and inoculation level $(D)$ on pollutant elimination yield at fixed temperature $\left(30^{\circ} \mathrm{C}\right.$, coded value 0) and incubation time (15 days, coded value 0) are displayed in Fig. 4a.

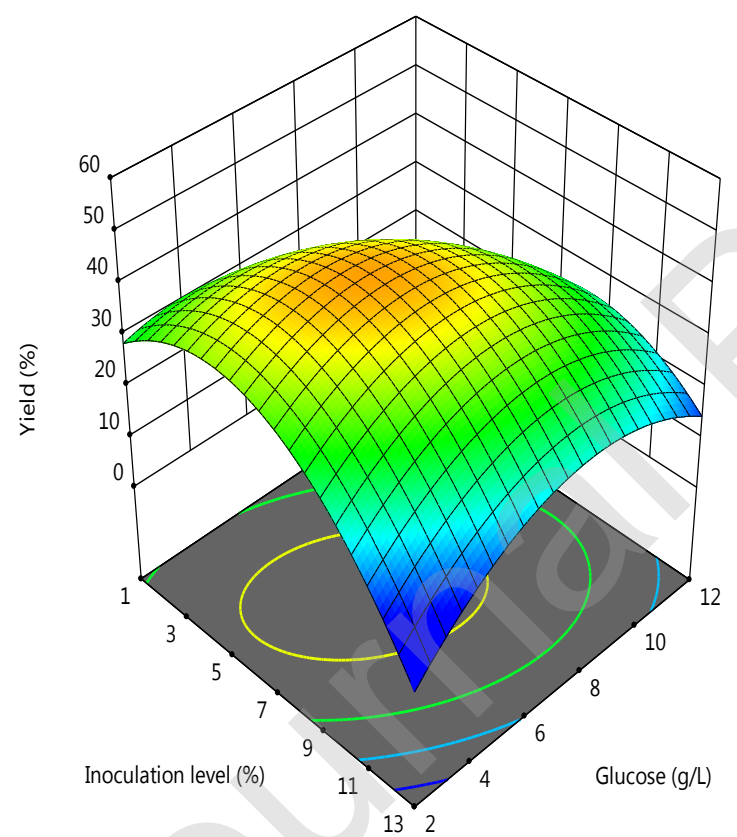

(a)

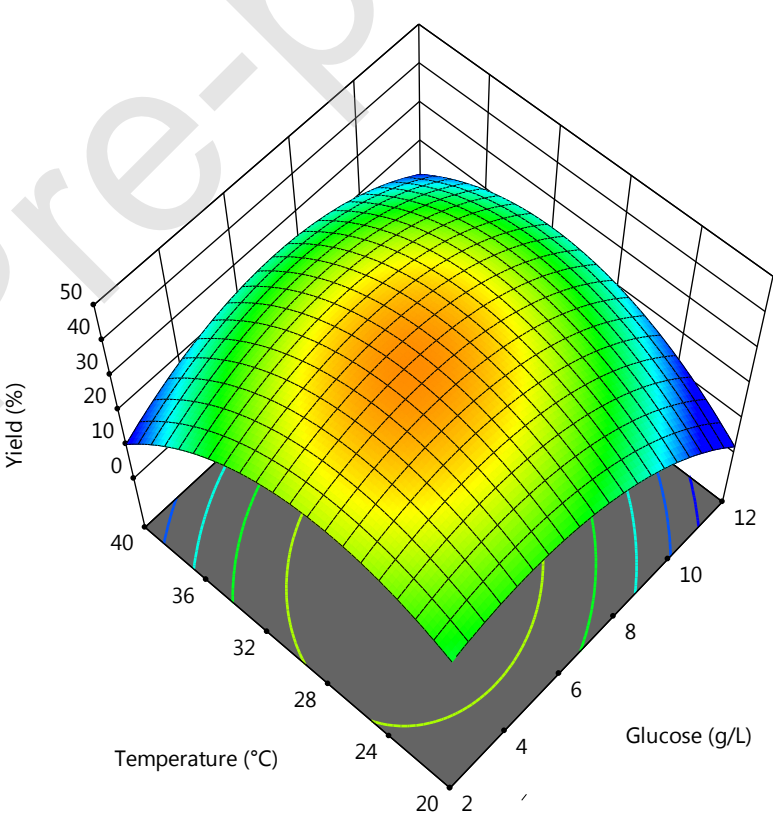

(b) 


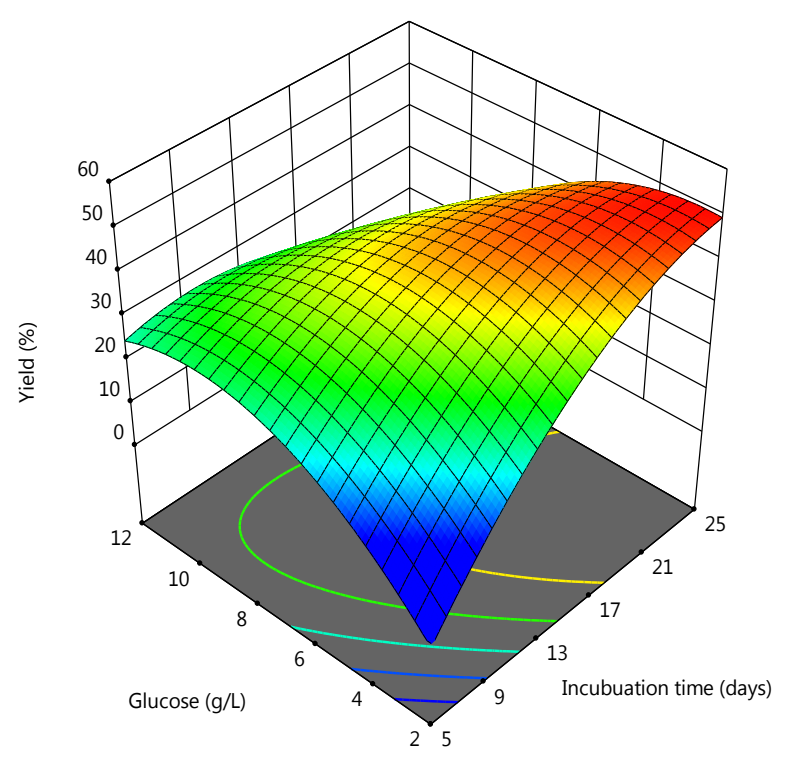

(c)

Fig. 4 Response surface plots presenting the combined effects of different significant parameters on the CLA degradation efficiency (a) inoculation level and glucose concentration; (b) glucose concentration and the temperature at fixed temperature; (c) glucose concentration and incubation time.

In this figure, it can be observed that the pollutant removal yield is clearly influenced by the concentration of the carbon co-substrate (glucose). The response increases with an increase in initial glucose concentration up to about 5-6 $\mathrm{g} \mathrm{L}^{-1}$. Then, it is observed that a further increase in glucose concentration exhibits a negative impact on CLA degradation. So, the maximum of CLA elimination by Streptomyces MIUG 4.89 lies about $6 \mathrm{~g} \mathrm{~L}^{-1}$ of glucose and $6 \%$ of inoculation level when incubation time and temperature levels correspond to the central point of the CCD. Under these conditions, the obtained CLA elimination yield is about $43 \%$. From Table 6 , it emerges that this value is only a local optimum in the corresponding surface. However, the shape of the surface suggests that a real optimum can be found as a function of temperature and inoculation level. Similarly, these results highlight the positive role of the addition of a second carbon source (glucose) on the elimination of the target molecule, as the removal efficiency had already been shown to remain very low when CLA was used as the sole source of carbon (Hemidouche et al., 2018; Popa Ungureanu et al., 2015a). In our work, this carbon source which is generally considered to be more easily assimilated by various microorganisms was supplied in the culture media at the beginning of the biodegradation tests. It is supposed that the second carbon source generally supports the cells growth and enzyme production accelerating the degradation of pollutant (Fakruddin and Quilty, 2005). Previous studies indicated that a readily available carbon source may act as an 
inducing agent for enzymes involved in the degradation of toxic pollutants (Chaudhuri and Wiesmann, 1995). Ziagova and Liakopoulou-Kyriakides (2007) reported an increase of degradation of diclofenac in the presence of acetate as carbon co-substrate. Similarly, Moreira et al. (2014) observed a total elimination of fluoxetine under co-metabolic conditions with acetate. The important role of the co-metabolic conditions in the elimination of toxic micro-pollutants was commonly reported in the literature, while no elimination was observed when these compounds were used as sole source of carbon and energy (Delgadillo-Mirquez et al., 2011). However, the negative effect observed beyond a glucose concentration of $6 \mathrm{~g} \mathrm{~L}^{-1}$ in Fig. 4a can be due to a catabolite repression by glucose. Loh and Wang (1997) and Satsangee and Ghosh (1990) also reported that high glucose concentrations affect the assimilation of some toxic pollutants, suggesting that such behavior can be due to a significant drop in $p H$ affecting the assimilation of the other substrates present in the culture medium (Fakhruddin and Quilty, 2005), as an acidic environment is not suitable for the aerobic dehalogenation of a toxic chlorinated compound by bacteria (Robinson et al., 2009).

According to Fig. 4a, the inoculation level also affects the CLA degradation. An increase in inoculation level up to $6 \%$ enhances the elimination efficiency in the temperature and incubation time conditions of the central point. This trend is in agreement with those reported by Ghevariya et al. (2011) and Abdelhay et al. (2008), showing that the inoculum size always plays an important role in the elimination of recalcitrant pollutants. In contrast, the CLA degradation decreases when the inoculation level is increased beyond 6\%. A similar trend was also reported by Mohana et al. (2008) who found that high concentrations of inoculum and glucose were inhibitory for the biodegradation of textile dye Direct Black 22. Thus, a proper choice of a combination between glucose concentration and inoculation levels is suitable to enhance the CLA elimination efficiency.

In Fig. 4b, the response surface plot displays the elimination yield with respect to the variation of temperature and initial glucose concentration, whereas the other two variables are kept constant at 15 days for the incubation time and $7 \%$ for the inoculation level (corresponding to the central point of the design). According to these results, a local maximum is also observed as a function of temperature and glucose concentration on the response surface of Fig. 4b. Under these conditions, the highest predicted value for the CLA degradation efficiency is about $42 \%$ when the glucose content is a bit lower than $6 \mathrm{~g} \mathrm{~L}^{-1}$ and for an incubation temperature close to $30^{\circ} \mathrm{C}$. In a biodegradation process, temperature has always been reported as a key factor affecting the biodegradation of toxic organic compounds (Zhao et al., 2008). It is well-known that the temperature affects not only the activity of 
microorganisms, but also the pollutant bioavailability (Bourguignon et al., 2014). Their activity is considered to be maximal at the optimal growth temperature. In the case of actinobacteria, this value is between $25-30^{\circ} \mathrm{C}$ (Aparicio et al., 2015) and Streptomyces belongs to this large group of bacteria. Benimeli et al. (2008) also found $30^{\circ} \mathrm{C}$ as the optimal temperature for the removal of lindane by a strain of Streptomyces isolated for contaminated soil. More recently, Bourguignon et al. (2014) selected the same value of temperature as optimal for the degradation of another pesticide, named methoxychlor. All these findings are in agreement with those of this work.

Then, Fig. 4c illustrates the response surface plot of the CLA biodegradation efficiency as a function of glucose concentration, incubation time, and their interaction. In this case, the inoculation level and temperature of incubation are held constant at $7 \%$ and $30^{\circ} \mathrm{C}$, respectively. The shape of the generated surface differs from Fig. $4 \mathrm{a}$ and Fig. $4 \mathrm{~b}$, and shows that pollutant removal tends to increase from less than $10 \%$ to more than $40 \%$ when a decrease in glucose content is accompanied by an increase in incubation time. This highlights the significance of the $C J$ term in eq. 4 , i.e. of the interaction between these two factors.

In addition, the response surface confirms that the incubation time may usually enhance the pollutant elimination efficiency. Figure 4c shows that CLA degradation increases rapidly up to 20 days and then tends to level-off when glucose content is between 2 and $6 \mathrm{~g}$ $\mathrm{L}^{-1}$. The positive effect of the incubation time on the removal of toxic compound could be expected. Cutright and Meza (2007) in their study devoted to the biodegradation of trichloroethylene (TCE) using response surface methodology observed that the overall degradation efficiency of TCE increased with the degradation time. More recently, Priyadharshini and Bathavatsalam (2016) reported that the reaction time strongly affected the removal of phenol, one of the most detected organic pollutants: they observed an increase of phenol degradation when the reaction time increased to the high level (5 days). Similarly, Ferradji et al. (2014) reported high elimination efficiency of naphthalene by three Streptomyces strains after 12 days of incubation; their results showed that increasing the incubation time improved the degradation potential of these strains. Similar results were also reported by Chaudhary et al. (2011) who studied the bioremediation of phenanthrene and pyrene. Thus, it appears that there is usually a positive effect of the incubation time on the degradation of these hazardous organic pollutants, confirming the results observed in our work. Conversely, when a high glucose content above, glucose was probably mainly used for growth, which reduced CLA consumption and removal yield at the same time. As a result, 
incubation time favors CLA removal only if nutritional and environmental conditions, such as co-metabolite content and probably incubation temperature, are properly chosen.

Then, Fig. 5a shows the combined effects between inoculation level and incubation temperature on the CLA degradation yield, while keeping the initial glucose concentration and the incubation time at $5 \mathrm{~g} \mathrm{~L}^{-1}$ and 20 days, respectively. A local maximum within the domain was observed in this surface, as in Fig. 4b. This was higher than 50\% yield and the parameters for this value of CLA biodegradation by Streptomyces MIUG 4.89 are close to $28^{\circ} \mathrm{C}$ and between $4-5 \%$ for the incubation temperature and the inoculation level, respectively. An increase in both factors above these values leads to a decrease in the process efficiency. It is well-known that use of an incubation temperature higher than the optimal growth temperature required by a microorganism may lead to a decrease in its metabolic activity, independently from inoculation level.
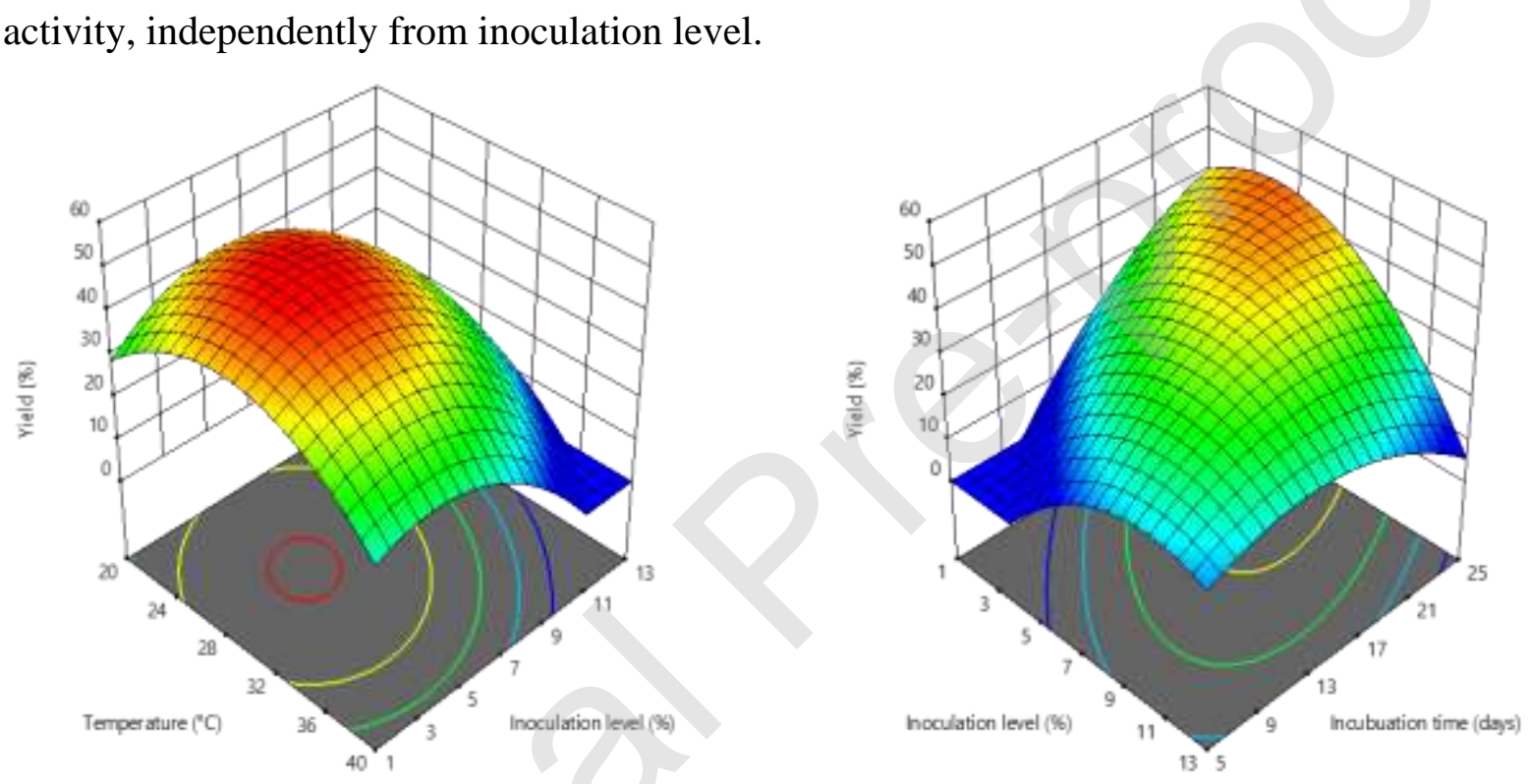

(a)

(b)

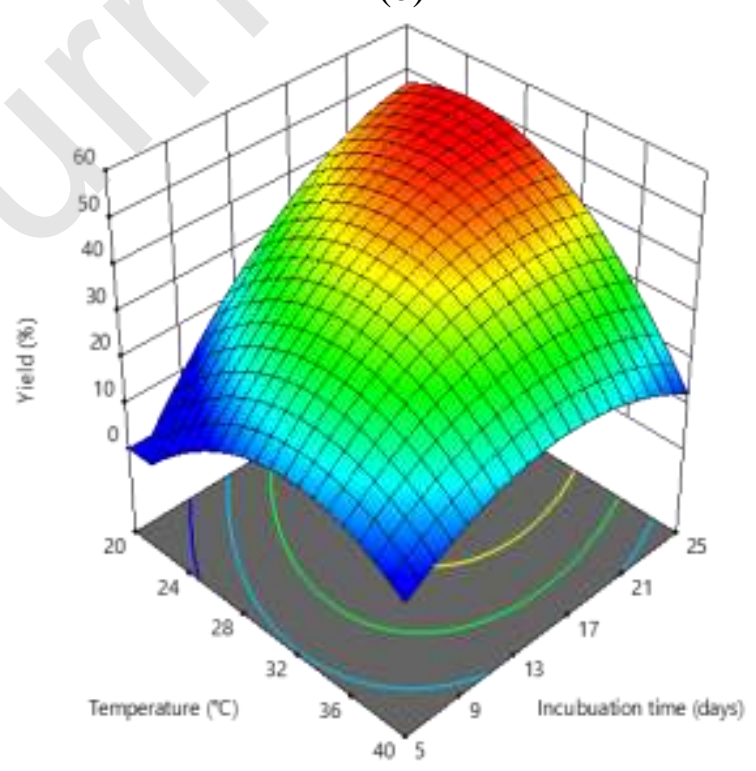


(c)

Fig. 5 Response surface plots for the CLA degradation efficiency presenting interactive effects between (a) the temperature and inoculation level; (b) incubation time and inoculation level; (c) incubation time and temperature.

Then, Fig. 5b displays the response surface as a function inoculation level and incubation time at fixed initial glucose concentration $\left(5 \mathrm{~g} \mathrm{~L}^{-1}\right)$ and temperature $\left(25^{\circ} \mathrm{C}\right)$. It presents the same shape as Fig. 4c, and the maximum appears at the limit of the domain. Thus, enhancing the biodegradation efficiency is induced by a negative interaction between the factors, i.e., an increase in incubation time and a decrease in inoculation level. However, if yield may be enhanced by a higher incubation time in a large range of inoculation level, an optimum always emerges for the inoculation level. In Fig. 5b, the highest value reported for CLA removal is achieved when inoculation level is about $4.5 \%(\mathrm{v} / \mathrm{v})$.

Finally, the mutual effects between the incubation time and temperature can also be assessed (Fig. 5c). In this case, the initial glucose concentration and inoculation level were fixed at $5 \mathrm{~g} \mathrm{~L}^{-1}$ and $7 \%$, respectively. The response surface presented the same shape as Fig. 5 b. This clearly indicates that a simultaneous increase in incubation time and temperature induces an increase of the biodegradation of pollutant up to an optimal level for temperature, while incubation time usually favors pollution removal, except at the highest temperature. Thus, temperature can be reduced when inoculation level is increased, while a too high temperature always exhibits a negative impact, as expected from previous comments.

As a conclusion, the observed trends seem in agreement with literature data and clearly highlight that an optimum value can be found in terms of temperature, glucose concentration, and inoculation level. Conversely, a maximum incubation time seems the most efficient in the range studied if temperature and nutritional conditions are optimized.

\section{Experimental validation of the optimum condition}

On the basis of the developed quadratic model and response surface plotted in the previous section, numerical optimization was carried out in the domain in which the model is robust, corresponding to $[-1 ;+1]^{4}$ in terms of coded levels. The results showed that a value of the predicted biodegradation yield of $53 \% \pm 1 \%$ could be achieved under submerged fermentation conditions using a culture media containing glucose as carbon co-substrate at an initial concentration of $5 \mathrm{~g} \mathrm{~L}^{-1}$, an inoculation level of $4.7 \%(\mathrm{v} / \mathrm{v})$, at $27.5^{\circ} \mathrm{C}$ and an 
incubation time of 20 days. As expected, these values are within the domain for temperature and inoculation level and correspond to level +1 for incubation time. However, glucose content corresponds to level -1 , which was not expected. A comparison with Table 6 rapidly shows that this value is higher than the experimental and predicted data obtained for the 29 treatments.

Subsequently, a series of three complementary runs were carried out using the predicted optimal biodegradation conditions. The obtained results were compared to the prediction provided by eq. 4 . The maximal elimination yield obtained through the biodegradation experiments was $54.4 \pm 0.3 \%$. This result is very close to the predicted value, thereby confirming the statistical significance and the robustness of the empirical model (eq. 4). In addition, the results obtained in this work under optimized culture conditions are very promising compared to the ones achieved in few previous studies carried out on specific microorganisms (Pseudomonas aeruginosa or Streptomyces spp.) or with mixed cultures evaluating the potential of different biological systems in the degradation of clofibric acid. As stated before, according to our knowledge the biodegradation of this molecule was not extensively studied probably because of its biorefractory characteristics. Table 7 summarizes the collected data related to the CLA elimination efficiency as well as the main experimental cultivation conditions. In some cases, an insignificant or a minor elimination yield was found while in other cases, superior biodegradation performances (between 30 and 51\%) were reported. The listed data demonstrated that the initial pollutant concentration and the culture conditions affect the CLA removal. Another evidence was that CLA biodegradation is enhanced in a cometabolic system. Under these conditions the addition of supplementary carbon source can serve to sustain the synthesis of biomass or can promote the activity of specific enzymes, which are responsible for the degradation of the target molecule. Also, it was observed that the used acclimated biomass represents another promising solution for the successful elimination of this molecule.

Table 7. Clofibric acid removal efficiencies achieved by using different biological systems and used cultivation conditions

\begin{tabular}{lllll}
\hline $\begin{array}{l}\text { Biological } \\
\text { system }\end{array}$ & Cultivation conditions & $\begin{array}{l}\text { CLA influent } \\
\text { concentration }\end{array}$ & $\begin{array}{l}\text { Removal } \\
\text { efficiency }\end{array}$ & Reference \\
\hline
\end{tabular}




\begin{tabular}{|c|c|c|c|c|}
\hline $\begin{array}{l}\text { Selecting } \\
\text { phosphorus } \\
\text { accumulating } \\
\text { organisms }\end{array}$ & $\begin{array}{l}\text { Lab-scale, MBBR, batch } \\
\text { mode, synthetic wastewater, } \\
\text { mixed culture conditions, } \\
20^{\circ} \mathrm{C}\end{array}$ & $50 \mu \mathrm{g} / \mathrm{L}$ & Insignificant & $\begin{array}{l}\text { Torresi et al. } \\
\text { (2019) }\end{array}$ \\
\hline $\begin{array}{l}\text { Activated } \\
\text { sludge }\end{array}$ & $\begin{array}{l}\text { Lab-scale aerobic conditions } \\
\text { continous mode, mineral } \\
\text { nutrient media, } 19^{\circ} \mathrm{C}\end{array}$ & $200-500 \mu \mathrm{g} / \mathrm{L}$ & $<30 \%$ & $\begin{array}{c}\text { Kosjek et al. } \\
\text { (2009) }\end{array}$ \\
\hline $\begin{array}{l}\text { Pseudomonas } \\
\text { aeruginosa } \\
\text { RZS9 }\end{array}$ & $\begin{array}{l}\text { Lab-scale aerobic } \\
\text { cometabolic conditions } \\
\text { batch mode, basal mineral } \\
\text { media, pH uncontrolled, } \\
\text { acclimated biomass }\end{array}$ & $1 \mathrm{mg} / \mathrm{L}$ & $35 \%$ & $\begin{array}{l}\text { Hemidouche et } \\
\text { al. (2018) }\end{array}$ \\
\hline $\begin{array}{l}\text { Mixed } \\
\text { microbial } \\
\text { culture }\end{array}$ & $\begin{array}{l}\text { Lab-scale SBR, mineral } \\
\text { media, } 25^{\circ} \mathrm{C}, \mathrm{pH} \\
\text { uncontrolled, unacclimated } \\
\text { biomass }\end{array}$ & $1 \mathrm{mg} / \mathrm{L}$ & $15 \%$ & $\begin{array}{l}\text { Salgado et al. } \\
\text { (2012) }\end{array}$ \\
\hline $\begin{array}{l}\text { Streptomyces } \\
\text { spp. }\end{array}$ & $\begin{array}{l}\text { Lab-scale batch bioreactor, } \\
\text { cometabolic conditions (a) } \\
\text { basal media, } 25^{\circ} \mathrm{C}, \mathrm{pH} \\
\text { uncontrolled, unacclimated } \\
\text { biomass }\end{array}$ & $200 \mu \mathrm{g} / \mathrm{L}$ & $35 \%$ & $\begin{array}{l}\text { Popa et al. } \\
\text { (2016) }\end{array}$ \\
\hline $\begin{array}{l}\text { Mixed } \\
\text { microbial } \\
\text { culture }\end{array}$ & $\begin{array}{l}\text { Lab-scale SBR, } \\
\text { cometabolic conditions }{ }^{(b)}, \\
25^{\circ} \mathrm{C}, \mathrm{pH} \text { uncontrolled, } \\
\text { acclimated biomass }\end{array}$ & $2 \mathrm{mg} / \mathrm{L}$ & $51 \%$ & $\begin{array}{l}\text { Salgado et al. } \\
\text { (2012) }\end{array}$ \\
\hline $\begin{array}{l}\text { Streptomyces } \\
\text { MIUG } 4.89\end{array}$ & $\begin{array}{l}\text { Lab-scale batch bioreactor, } \\
\text { cometabolic conditions (a) } \\
\text { basal media, } 25^{\circ} \mathrm{C}, \mathrm{pH} \\
\text { uncontrolled, unacclimated } \\
\text { biomass }\end{array}$ & $200 \mu \mathrm{g} / \mathrm{L}$ & $54.4 \%$ & This study \\
\hline
\end{tabular}

SBR: sequenching batch reactor; MBBR: moving bed biofilm reactor

(a) cometabolic conditions with glucose;

(b) cometabolic conditions with propanil.

Products of the transformation of clofibric acid by Streptomyces MIUG 4.89

The HPLC-DAD analysis of the samples collected during the performed biodegradation tests revealed the presence of new chromatographic peaks in addition to the one observed for the parent molecule. It should be noticed that these peaks were absent from the monitored samples corresponding to the initial incubation time. According to these results, the detected supplementary peaks can be due to the conversion of CLA by Streptomyces MIUG 4.89 into organic biotransformation products with the cultivation time. Moreover, another evidence for the degradation of the target molecule is the decrease of the measured peak area corresponding to CLA during the incubation period. However, in all the 
analyzed samples CLA was not completely removed from the system at the end of the incubation time period. Three metabolites were identified from by HPLC-DAD chromatograms after injection of corresponding standards. The first generated bioreaction intermediate was detected at a retention time $(\mathrm{t})$ of $7.24 \mathrm{~min}$. and was identified as 4chlorophenol $\left(\mathrm{C}_{6} \mathrm{H}_{5} \mathrm{ClO}\right.$, product 1$)$. It is presumed to be formed by cleavage of ether bond of the parent molecule. Similar findings were previously reported by Kosjek et al. (2009) during the microbial fate study performed on the same pharmaceutically active substance. However, in our work based on the collected chromatograms we were unable to detect this toxic molecule in the samples taken from the cultures at the end of the cultivation time because its concentration in the sample is much lower than its instrumental detection limit because of its possible transformation. In their studies, Kargi and Konya (2007) and Buitrón and MorenoAndrade (2011) reported on the biodegradability of 4-chlorophenol (4-CP) and on the enhancement of its removal with the hydraulic retention time in the reactor. Other workers highlighted that in the case of Alcaligenes eutrophus this molecule can serve as cometabolite (Hill et al., 1996) or is recognized as a breakdown product formed during the photolytic and photocatalytic degradation of clofibric acid (Doll and Frimmel, 2004). Also, Doll and Frimmel (2004) indicated that the reaction conducting to 4-CP formation represented a minor degradation route in the oxidation of CLA under acidic conditions. In the study of Evagelista et al. (2011), it was found that CLA present in solution was only transformed into ethyl clofibrate by Rhodococcus rhodochorus after 20 days of acclimatization. The other two detected metabolites were $\alpha$-hydroxyisobutyric and lactic acids $\left(\mathrm{C}_{4} \mathrm{H}_{8} \mathrm{O}_{3}-\mathrm{t}_{\mathrm{r}} 2.48 \mathrm{~min}\right.$, and $\mathrm{C}_{3} \mathrm{H}_{6} \mathrm{O}_{3}-\mathrm{t}_{\mathrm{r}} 2.28 \mathrm{~min}$, respectively). They were detected at $250 \mathrm{~nm}$ and $259 \mathrm{~nm}$, respectively. The last one was mainly identified at the end of the incubation period. $\alpha$-hydroxyisobutyric (product 1) could be formed by pathway involving dechlorination and ring opening reactions yielding to this metabolite (pathway II, Fig. 6). This pathway may occur in parallel with the one leading to 4-CP (pathway I, Fig. 6) explaining its presence in the culture during the biodegradation reaction. Its accumulation, however, did not affect the CLA biodegradation because of the presence of lactic acid in the analyzed samples. Prior to this study, other ringopening reaction intermediates were found during the ozonation of clofibric acid (Rosal et al, 2009). According to our data and to other previous works (Doll and Frimmel, 2004; Kosjek et al., 2009; Zhu et al., 2019) a possible biotransformation mechanism including two different pathways is presented in Fig. 6 for the biodegradation of CLA by Streptomyces MIUG 4.89 
under aerobic culture conditions. Different possible metabolites indicated (a), (b), (c) (d) in this figure were not detected in this work.

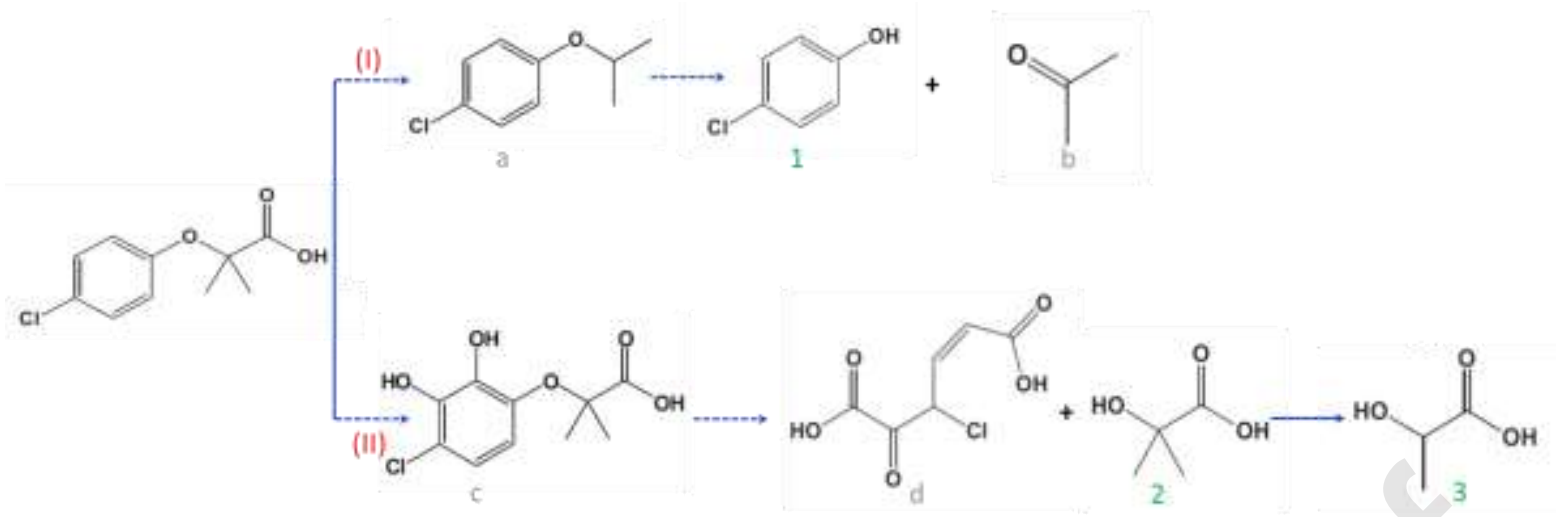

Fig. 6 Possible mechanism for biotransformation of clofibric acid by Streptomyces MIUG 4.89.

A possible explanation is that these reaction intermediates are present in the collected samples at concentration levels, which are below the instrumental quantification limit of the used chromatographic system or because of their chemical instability during the cultivation conditions.

\section{Conclusions}

To the best of authors' knowledge, this is the first study reporting on the optimization of the biodegradation of clofibric acid through response surface methodology. Thus, four significant factors among ten tested were shown to significantly affect the biodegradation efficiency of CLA by the strain of Streptomyces MIUG 4.89: namely, co-substrate content, inoculation level, temperature, and incubation time. The predicted optimal conditions for the degradation of this persistent drug metabolite were an initial glucose concentration of $5 \mathrm{~g} \mathrm{~L}^{-1}$, an inoculation level of $4.7 \%(\mathrm{v} / \mathrm{v})$, at $27.5^{\circ} \mathrm{C}$ with an incubation time of 20 days. Under these conditions, the model predicted that $53 \% \pm 1 \%$ of the pollutant content was removed, while an experimental biodegradation yield of $54.4 \%$ was achieved. It must also be pointed out that the maximum yield reached in this work is much higher than those reported in the literature for the biodegradation of this molecule using unacclimated biomass. Thus, the results demonstrate that the strain of Streptomyces MIUG 4.89 has an enormous potential in the degradation of clofibric acid.

More generally, the results obtained in this work are of environmental significance, taking into account the issue that must be faced, to date, for the treatment of refractory organic pollutants. There is, indeed, an increased interest in exploring new microorganisms in 
order to find novel original efficient solutions for the bioremediation of emergent organic pollutants. In this context, the results presented in this work highlight the scope of the utilization of bacteria belonging to the genus of Streptomyces as promising candidates for environmental biotechnology applications.

Now, for further work, the optimum culture conditions reported above for the removal of clofibric acid using the strain of Streptomyces MIUG 4.89 will be the starting point for further biodegradation studies in bioreactors under the batch mode using dilute wastewater effluents and to investigate more deeply the mechanism involved in the elimination of the target molecule.

\section{Declaration of interests}

The authors declare that they have no known competing financial interests or personal relationships that could have appeared to influence the work reported in this paper. 


\section{References}

Abdelhay, A., Magnin, J.P., Gondrexon, N., Baup, S., Willison, J., 2008. Optimization and modeling of phenanthrene degradation by Mycobacterium sp. 6PY1 in a biphasic medium using Response-Surface Methodology. Appl. Microbiol. Biotechnol. 78, 881888.

Abdessalem, A.K., Oturan, N., Bellakhal, N., Dachraoui, M., Oturan, M.A., 2008.

Experimental design methodology applied to electro-Fenton treatment for degradation of herbicide chlortoluron. Appl. Catal. B. 78, 334-341.

Ambashta, R.D., Sillanpää, M., 2011. Experimental design of application of nanoscale ironnickel under sonication and static magnetic field for mixed waste remediation. J. Hazard. Mater. 189, 167-172.

Aparicio, J.D., Simón Solá, M.Z., Benimeli, C.S., Amoroso, M.J., Polti, M.A., 2015. Versatility of Streptomyces sp. M7 to bioremediate soils co-contaminated with Cr (VI) and lindane. Ecotoxicol. Environ. Saf. 116, 34-39.

Atlas, R.M., 2010. Handbook of microbiological media. Boca. Raton, FL: CRC Press. Bankar, S.B., Singhal, R.S., 2010. Optimization of poly-epsilon-lysine production by Streptomyces noursei NRRL 5126. Bioresour. Technol. 101, 8370-8375.

Beg, Q.K., Sahai, V., Gupta, R., 2003. Statistical media optimization and alkaline protease production from Bacillus mojavensis in a bioreactor. Process. Biochem. 39, 203-209.

Benimeli, C.S., Fuentes, M.S., Abate, C.M., Amoroso, M.J., 2008. Bioremediation of lindane-contaminated soil by Streptomyces sp. M7 and its effects on Zea mays growth. Int. Biodeterior. Biodegrad. 61, 233-239.

Bourguignon, N., Fuentes, M.S., Benimeli, C.S., Cuozzo, S.A., Amoroso, M.J., 2014. Aerobic removal of methoxychlor by a native Streptomyces strain: Identification of intermediate metabolites. Int. Biodeterior. Biodegrad. 96, 80-86.

Buitrón, G., Moreno- Andrade, I., 2011. Biodegradation kinetics of a mixture of phenols in a sequencing batch moving bed biofilm reactor under starvation and shock loads. J. Chem. Technol. Biotechnol. 86, 669-674.

Chaudhary, P., Sharma, R., Singh, S.B., Nain, L., 2011. Bioremediation of PAH by Streptomyces sp.. Bull. Environ. Contam. Toxicol. 86, 268-271.

Chaudhuri, B.K., Wiesmann, U., 1995. Enhanced anaerobic degradation of benzene by enrichment of mixed microbial culture and optimization of the culture medium. Appl. Microbiol. Biotechnol. 43, 178-187. 
Cutright, T.J., Meza, L. 2007. Evaluation of the aerobic biodegradation of trichloroethylene via Surface Response Methodology. Env. Int. 33, 338-345.

Dayana Priyadharshini, S., Bakthavatsalam, A.K., 2016. Optimization of phenol degradation by the microalga Chlorella pyrenoidosa using Plackett-Burman Design and Response Surface Methodology. Bioresour. Technol. 207, 150-156.

De Coninck, J., Bouquelet, S., Dumortier, V., Duyme, F., Verdier-Denantes, I., 2000. Industrial media and fermentation processes for improved growth and protease production by Tetrahymena thermophila BIII. J. Ind. Microbiol. Biotechnol. 24, 285290.

Delgadillo-Mirquez, L., Lardon, L., Steyer, J.P., Patureau, D., 2011. A new dynamic model for bioavailability and cometabolism of micropollutants during anaerobic digestion. Water Res. 45, 4511-4521.

Doll, T.E., Frimmel, F.H., 2004. Kinetic study of photocatalytic degradation of carbamazepine, clofibric acid, iomeprol and iopromide assisted by different $\mathrm{TiO} 2$ materials - determination of intermediates and reaction pathways. Water Res. 38, 955964.

Elibol, M., 2004. Optimization of medium composition for acti-norhodin production by Streptomyces coelicolor A3 (2) with Response Surface Methodology. Proc. Biochem. 39, 1057-1062.

Fakhruddin, A.N.M., Quilty, B., 2005. The influence of glucose and fructose on the degradation of 2-chlorophenol by Pseudomonas putida CP1. World J. Microbiol. Biotechnol. 21, 1541-1548.

Favier, L., Simion, A.I., Matei, E., Grigoras, C.G., Kadmi, Y., Bouzaza, A., 2016. Photocatalytic oxidation of a hazardous phenolic compound over $\mathrm{TiO}_{2}$ in a batch system. Environ. Eng. Manage. J. 15, 1059-1067.

Ferradji, F.Z., Mnif, S., Badis, A., Rebbani, S., Fodil, D., Eddouaouda, K., Sayadi, S., 2014. Naphthalene and crude oil degradation by biosurfactant producing Streptomyces spp. isolated from Mitidja plain soil (North of Algeria). Int. Biodeterior. Biodegrad. 86, 300308.

Fu, X.T., Lin, H., Kim, S.M., 2009. Optimization of medium composition and culture conditions for agarase production by Agarivorans albus YKW-34. Proc. Biochem. 4410, 1158-1163.

Gao, H., Liu, M., Liu, J.T., Dai, H.Q., Zhou, X.L., Liu, X.Y., Zhuo, Y., Zhang, W.Q., Zhang, L.X., 2009. Medium optimization for the production of avermectin B1a by Streptomyces 
avermitilis 14-12A using Response Surface Methodology. Bioresour. Technol. 100, 4012-4016.

García-Galán, M.J., Arashiro, L., Santos, L.H.M.L.M, Insa, S., Rodríguez-Mozaz, S., Barceló, D., Ferrer, I., Garfí, M., 2020. Fate of priority pharmaceuticals and their main metabolites and transformation products in microalgae-based wastewater treatment systems. J. Hazard. Mater., 390, 121771,

Ghevariya, C.M., Bhatt, J.K., Dave, B.P., 2011. Enhanced chrysene degradation by halotolerant Achromobacter xylosoxidans using Response Surface Methodology. Bioresour. Technol. 102, 9668-9674.

Grigoras, C.G., Simion, A.-I., Favier, L., Gavrila, L. (2020). Congo red removal from aqueous effluents by adsorption on cherry stones activated carbon. Environ. Eng. Manage. J. 19, 247-254.

Harja, M., Sescu, A.-M, Favier, L., Lutic D., 2020. Doping titanium dioxide with palladiun for enhancing the photocatalytic decontamination and mineralization of a refractory water pollutant. Rev. Chim. 71, 145-152.

Hemidouche, S., Favier, L., Amrane, A., Dabert, P., Le Roux, S., Sadaoui, Z., 2018. Successful biodegradation of a refractory pharmaceutical compound by an indigenous phenol-tolerant Pseudomonas aeruginosa strain. Water Air Soil Pollut. 229, 103.

Hill, G., Milne, B., Nawrocki, P., 1996. Cometabolic degradation of 4-chlorophenol by Alcaligenes eutrophus. Appl .Microbiol. Biotechnol. 46, 163-168.

Hopwood, D.A., 1967. Genetic analysis and genome structure in Streptomyces coelicolor. Bact. Rev. 31, 373-403.

Im, J.K., Cho, I.H., Kim, S.K., Zoh, K.D., 2012. Optimization of carbamazepine removal in $\mathrm{O}_{3} / \mathrm{UV} / \mathrm{H}_{2} \mathrm{O}_{2}$ system using a Response Surface Methodology with Central Composite Design. Desalination 285, 306-314.

Jabeen, H., Iqbal, S., Anwar, S., Parales, R.E., 2015. Optimization of profenofos degradation by a novel bacterial consortium PBAC using Response Surface Methodology. Int. Biodeterior. Biodegrad. 100, 89-97.

Kadmi, Y., Favier, L., Simion, A.-I., Rusu, L., Pacala, M.L., Wolbert, D. (2017). Measurement of pollution levels of N-nitroso compounds of health concern in water using ultra-performance liquid chromatography-tandem mass spectrometry, Process Saf. Environ. 108, 7-17.

Kargi, F., Konya, I., 2007. Para-chlorophenol containing synthetic wastewater treatment in an activated sludge unit: Effects of hydraulic residence time, J. Environ. Manage. 84, 20- 
26.

Khetan, S.K., Collins, T.J., 2007. Human pharmaceuticals in the aquatic environment: a challenge to green chemistry. Chem. Rev. 107, 2319-2364.

Klavarioti, M., Mantzavinos, D., Kassinos, D., 2009. Removal of residual pharmaceuticals from aqueous systems by advanced oxidation process. Environ. Int. 35, 402-417.

Kosjek, T., Heath, E., Pérez, S., Petrović, M., Barceló, D., 2009. Metabolism studies of diclofenac and clofibric acid in activatedPo sludge bioreactors using liquid chromatography with quadrupole - time-of-flight mass spectrometry. J. Hydrol. 372, 109-117.

Kummerer, K., 2010. Pharmaceuticals in the environment. Ann. Rev. Environ. Res. 35, 57-75.

Lai, L.S.T., Pan, C.C., Tzeng, B.K., 2003. The influence of medium design on lovastatin production and pellet formation with a high-producing mutant of Aspergillus terreus in submerged cultures. Proc. Biochem. 38, 1317-1326.

Lee, H., Song, M., Hwang, S., 2003. Optimizing bioconversion of deproteinated cheese whey to mycelia of Ganoderma lucidum. Proc. Biochem. 38, 1685-1693.

Li, C., Bai, J., Cai, Z., Ouyang, F., 2002. Optimization of a cultural medium for bacteriocin production by Lactococcus lactis using Response Surface Methodology. J. Biotechnol. 93, 27-34.

Li, X., Ouyang, J., Xu, Y., Chen, M., Song, X., Yong, Q., Yu, S., 2009. Optimization of culture conditions for production of yeast biomass using bamboo wastewater by Response Surface Methodology. Bioresour. Technol. 100, 3613-3617.

Loh, K.C., Wang, S.J., 1997. Enhancement of biodegradation of phenol and a nongrowth substrate 4-chlorophenol by medium augmentation with conventional carbon sources. Biodegradation 8, 329-338.

Majumder, A., Goyal, A., 2007. Enhanced production of exocellular glucansucrase from Leuconostoc dextranicum NRRL B-1146 using Response Surface Method. Bioresour. Technol. 99, 3685-3691.

Marco-Urrea, E., Perez-Trujillo, M., Vicent, T., Caminal, G., 2009. Ability of white-rot fungi to remove selected pharmaceuticals and identification of degradation products of ibuprofen by Trametes versicolor. Chemosphere 74, 765-72.

Matamoros, V., Garcia, J., Boyona, J.M., 2008. Organic micropollutant removal in a full-scale surface flow constructed wetland fed with secondary effluent. Water Res. 42, 653-660.

Mohana, S., Shrivastava, S., Divecha, J., Madamwar, D., 2008. Response Surface Methodology for optimization of medium for decolorization of textile dye Direct Black 
22 by a novel bacterial consortium. Bioresour. Technol. 99, 562-569.

Mohanty, S.S., Jena, H.M., (2019). Degradation kinetics and mechanistic study on herbicide bioremediation using hyper butachlor-tolerant Pseudomonas putida G3. Process Saf. Environ. 125, 172-181.

Moreira, I.S., Ribeiro, A.R., Afonso, C.M., Tiritan, M.E., Castro, P.M.L., 2014. Enantioselective biodegradation of fluoxetine by the bacterial strain Labrys portucalensis F11. Chemosphere 111, 103-111.

Pan, C.M., Fan, Y.T., Xing, Y., Hou, H.W., Zhang, M.L., 2008. Statistical optimization of process parameters on biohydrogen production from glucose by Clostridium sp Fanp2. Bioresour. Tehnol. 99, 3146-3154.

Plakett, R.L., Burmann, J.P., 1946. The design of optimum of multifactorial experiments. Biometrika 33, 305-325.

Polti, M.A., Aparicio, J.D., Benimeli, C.S., Amoroso, M.J., 2014. Simultaneous bioremediation of $\mathrm{Cr}(\mathrm{VI})$ and lindane in soil by actinobacteria. Int. Biodeterior. Biodegrad. 88, 48-55.

Popa, C., Favier, L., Dinica, R., Semrany, S., Djelal, H., Amrane, A., Bahrim, G., 2014. Potential of newly wild Streptomyces stains as agents for the biodegradation of a recalcitrant pharmaceutical, carbamazepine. Environ. Technol. 35, 3082-3091.

Popa Ungureanu, C., Balaes, T., Favier, L., Tanase, C., Bahrim, G., 2015a. White-rot fungus implications in clofibric acid biodegradation. Rom. Biotech. Lett. 20, 10388-10398.

Popa Ungureanu, C., Favier, L., Bahrim, G., 2016. Screening of soil bacteria as potential agents for drugs biodegradation: case study with clofibric acid. J. Chem. Technol. Biotechnol. 91, 1646-1653.

Popa Ungureanu, C., Favier, L., Bahrim, G., 2018. Optimization of different key culture conditions for enhanced biodegradation of a refractory emerging pollutant by a bacterial isolate through a statistical approach. In: Kallel A., Ksibi M., Ben Dhia H., Khélifi N. (eds) Recent Advances in Environmental Science from the Euro-Mediterranean and Surrounding Regions. EMCEI 2017, Springer, 259-260.

Prpich, P.G., Daugulis, A.G., 2005. Enhanced biodegradation of phenol by a microbial consortium in a solid liquid two-phase partitioning bioreactor. Biodegradation 16, 329639.

Puri, S., Beg, Q.K., Gupta, R., 2002. Optimization of alkaline protease production from Bacillus sp. using Response Surface Methodology. J. Curr. Microbiol. 44, 286-290.

Ravel, J., Amoroso, M.J., Colwell, R.R., Hill, R.T., 1998. Mercury-resistant actinomycetes from 
the Chesapeake bay. FEMS Microbiol. Lett. 162, 177-184.

Rigas, F., Dritsa, V., Marchant, R., Papadopoulou, K., Avramides, E.J., Hatzianestis, I., 2005.

Biodegradation of lindane by Pleurotus ostreatus via Central Composite Design.

Environ. Int. 31, 191-196.

Robinson, C., Barry, D.A., McCarty, P.L., Gerhard, J.I., Kouznetsova, I., 2009. pH control for enhanced reductive bioremediation of chlorinated solvent source zones. Sci. Total Environ. 407, 4560-4573.

Rosal, R., Gonzalo, M.S., Boltes, K., Letón, P., Vaquero, J.J., García-Calvo E., 2009. Identification of intermediates and assessment of ecotoxicity in the oxidation products generated during the ozonation of clofibric acid. J. Hazard. Mater. 172, 1061-1068.

Rosales, E., Sanromán, M.A., Pazos, M., 2012. Application of Central Composite faceCentered Design and Response Surface Methodology for the optimization of electroFenton decolorization of Azure B dye. Environ. Sci. Pollut. Res. 19, 1738-1746.

Salgado, R., Oehmen, A., Carvalho, G., Noronha, J.P., Reis, M.A.M., 2012. Biodegradation of clofibric acid and identification of its metabolites. J. Hazard. Mater. 241, 182-189.

Satsangee, R., Ghosh, P., 1990. Anaerobic degradation of phenol using an acclimated mixed culture. Appl. Microbiol. Biotechnol. 34, 127-130.

Sescu, A.M., Harja, M., Favier, L., Berthou Oughebbi, L., Gomez de Castro, C., Pui, A., Lutic, D., 2020. Zn/La Mixed oxides prepared by coprecipitation: synthesis, characterization and photocatalytic studies. Materials 13, 4916.

Sonwani, R. K., Giri, B.G, Singh, R.S., Rai, B.N., 2019. Studies on optimization of naphthalene biodegradation using surface response methodology: Kinetic study and performance evaluation of a pilot scale integrated aerobic treatment plant. Process Saf. Environ. 132, 240-248.

Tanyildizi, M.S., Dursun, O., Elibol, M., 2005. Optimization of $\alpha$-amylase production by Bacillus sp. using Response Surface Methodology. Process. Biochem. 40, 2291-2296.

Torresi, E., Tang, K., Deng, J., Sund, C., Smets, B.F., Christensson, M., Andersen, H.R., 2019. Removal of micropollutants during biological phosphorus removal: Impact of redox conditions in MBBR. Sci. Tot. Environ. 663, 496-506.

Tzikalos, N., Belessi, V., Lambropoulou, D., 2013. Photocatalytic degradation of reactive red 195 using anatase/brookite $\mathrm{TiO}_{2}$ mesoporous nanoparticles: optimization using Response Surface Methodology (RSM) and kinetics studies. Environ. Sci. Pollution Res. 20, 2305-2320.

Ungureanu Popa, C., Favier, L., Bahrim, G., Amrane, A., 2015b. Response Surface 
optimization of experimental conditions for carbamazepine biodegradation by Streptomyces MIUG 4.89. New Biotechnol. 32, 348-357.

Yehya, T., Favier, L., Kadmi, Y., Audonnet, F., Fayad, N., Gavrilescu, M., Vial, C., 2015.

Removal of carbamazepine by electrocoagulation: investigation of some key operational parameters. Environ. Eng. Manage. J. 14, 639-645.

Yehya, T., Favier, L., Audonnet, F., Fayad, N., Bahry, H., Bahrim, G.E., Vial, C., 2020.

Towards a better understanding of the removal of carbamazepine by Ankistrodesmus braunii: investigation of some key parameters. Appl. Sci. 10, 8034.

Zhang, C.H., Ma, Y.J., Yang, F.X., Liu, W., Zhang, Y.D., 2009. Optimization of medium composition for butyric acid production by Clostridium thermobutyricum using Response Surface Methodology. Bioresour. Technol. 100, 284-4288.

Zhang, D.Q., Gersberg, R.M., Zhu, J., Hua, T., Jinadasa, K.B.S.N., Tan, S.K., 2012. Batch versus continuous feeding strategies for pharmaceutical removal by subsurface flow constructed wetland. Environ. Pollut. 167, 124-131.

Zhu, K., Wang, X., Geng, M., Chen, D., Lin H., Zhang H., 2019. Catalytic oxidation of clofibric acid by peroxydisulfate activated with wood-based biochar: Effect of biochar pyrolysis temperature, performance and mechanism. Chem. Eng. J. 374, 1253-1263.

Ziagova, M., Liakopoulou-Kyriakides, M., 2007. Comparison of cometabolic degradation of 1,2-dichlorobenzene by Pseudomonas sp. and Staphylococcus xylosus. Enzyme Microb. Technol. 40, 1244-1250. 